\title{
Mesoscale model forecast verification during monsoon 2008
}

\author{
Raghavendra Ashrit and Saji Mohandas \\ National Centre for Medium Range Weather Forecasting (Ministry of Earth Sciences) A-50, \\ Institutional Area-II, Sector-62, Noida (UP) 201 307, India.
}

There have been very few mesoscale modelling studies of the Indian monsoon, with focus on the verification and intercomparison of the operational real time forecasts. With the exception of Das et al (2008), most of the studies in the literature are either the case studies of tropical cyclones and thunderstorms or the sensitivity studies involving physical parameterization or climate simulation studies. Almost all the studies are based on either National Center for Environmental Prediction (NCEP), USA, final analysis fields (NCEP FNL) or the reanalysis data used as initial and lateral boundary conditions for driving the mesoscale model.

Here we present a mesoscale model forecast verification and intercomparison study over India involving three mesoscale models: (i) the Weather Research and Forecast (WRF) model developed at the National Center for Atmospheric Research (NCAR), USA, (ii) the MM5 model developed by NCAR, and (iii) the Eta model of the NCEP, USA. The analysis is carried out for the monsoon season, June to September 2008. This study is unique since it is based entirely on the real time global model forecasts of the National Centre for Medium Range Weather Forecasting (NCMRWF) T254 global analysis and forecast system. Based on the evaluation and intercomparison of the mesoscale model forecasts, we recommend the best model for operational real-time forecasts over the Indian region.

Although the forecast mean $850 \mathrm{hPa}$ circulation shows realistic monsoon flow and the monsoon trough, the systematic errors over the Arabian Sea indicate an easterly bias to the north (of mean flow) and westerly bias to the south (of mean flow). This suggests that the forecasts feature a southward shift in the monsoon current. The systematic error in the $850 \mathrm{hPa}$ temperature indicates that largely the WRF model forecasts feature warm bias and the MM5 model forecasts feature cold bias. Features common to all the three models include warm bias over northwest India and cold bias over southeast peninsula. The $850 \mathrm{hPa}$ specific humidity forecast errors clearly show that the Eta model features dry bias mostly over the sea, while MM5 features moist bias over large part of domain. The RMSE computed at different levels clearly establish that WRF model forecasts feature least errors in the predicted free atmospheric fields. Detailed rainfall forecast verification further establishes that the WRF model forecast rainfall skill remains more or less same in day-2 and day-3 as in day-1, while the forecast skill in the MM5 and Eta models, deteriorates in day-2 and day-3 forecasts.

\section{Introduction}

The numerical weather prediction (NWP) models have been reasonably successful in the last two decades for large-scale medium-range weather forecasting. However, accurate prediction of precipitation remains a challenge. Mesoscale models, forced by the initial and boundary conditions from the global model forecasts, are widely used to obtain regional forecasts at high spatial and temporal resolution. They account for the influence of detailed topography, land cover, and

Keywords. Mesoscale; monsoon; forecast; rainfall; skill score. 
vegetation, which are either missing or smoothed in global models. Several operational forecasting agencies use the mesoscale models for detailed weather forecasts over small geographical regions. The mesoscale models are important for the simulation and prediction of high impact severe weather systems like the tropical cyclones, monsoon depressions, thunderstorms, western disturbances, etc., to name a few. Such models remain important tools for any operational NWP centre, since it is possible to carry our very high-resolution model integrations on a nested grid with a wide variety of options for the parameterization of physical processes. The global models do not have such privileges and, they are very expensive to carry out integrations at high resolutions.

At the National Centre for Medium Range Weather Forecasting (NCMRWF), three mesoscale models namely the Weather Research and Forecast (WRF) model, the MM5 model and the Eta model have been used for operational/real-time forecasting of mesoscale systems. Both models, the WRF and the MM5 have been developed and supported by the National Center for Atmospheric Research (NCAR), USA, and are used for operational and research applications. The Eta Model is developed at the National Center for Environmental Prediction (NCEP), USA, and is mainly used in the operational forecasting applications. These three models are used for high resolution forecasts up to 72 hours. The operational model forecasts are carried out at different horizontal and vertical resolutions and varying configurations of physical parameterization schemes (see table 1) to develop forecast products for different applications.

The purpose of this paper is to make a comprehensive statistical study of the three mesoscale model forecasts, evaluate their performance for a complete monsoon season of 2008 and recommend the best model for operational real-time forecasts over the Indian region. Studies involving the mesoscale modelling of the Indian monsoon with focus on verification and intercomparison of the model performance have been very few. With the exception of Das et al (2008) (discussed later in this section), most of the studies in the literature are: (i) case studies of tropical cyclones (Patra et al 2000; Mohanty et al 2004; Singh et al 2005; Ashrit et al 2006; Pattanayak and Mohanty 2008; Pattanayik and Rama Rao 2009), thunderstorms (Litta and Mohanty 2008), cloudbursts (Das et al 2006); (ii) sensitivity studies involving physics (Bhaskar Rao and Prasad 2006; Trivedi et al 2006; Mandal and Mohanty 2006; Das et al 2007; Rakesh et al 2007); and (iii) climate simulation studies (Bhaskaran et al 1996; Ji and Vernekar 1997; Bhaskar Rao et al 2004; Ratnam and Krishna Kumar 2005; Dash et al 2006). None of the mesoscale modelling studies of the Indian monsoon in the literature provides detailed verification and intercomparison of the forecasts for an entire monsoon period. Almost all the studies listed above are based on either NCEP final analysis fields (NCEP FNL) or the NCEP/NCAR reanalysis data used as initial and lateral boundary conditions for driving the mesoscale model. This study is unique since it is based on the real time global model forecasts of NCMRWF T254 system (Rajagopal et al 2007).

In an earlier study, Das et al (2008) discussed the performance of the four mesoscale models namely, the MM5, ETA, RSM and WRF, in short range weather forecasting during monsoon season, i.e., June, July, August and September (JJAS hereafter) 2006. The initial and lateral boundary conditions for the mesoscale models were derived from the coarse resolution T80L18 global model of NCMRWF. The evaluation based upon comparisons between observations (model initial analysis) and (i) the forecasts of wind, temperature, specific humidity, geopotential height, rainfall, (ii) the systematic errors, root mean square errors (RMSE) of the forecasts, and (iii) specific events like the monsoon depressions, concluded that it is very difficult to address the question of which model performs best over the Indian region? This question is revisited in the present study based on the three operational mesoscale models (WRF, MM5 and Eta) used at NCMRWF during the monsoon season (JJAS) 2008. Like in the earlier study (Das et al 2008), the scientific scope is limited since the approach of the paper is statistical.

It is important to note that:

- The present study uses the high resolution T254 ( 50 km grid spacing) model analysis and forecasts as initial and lateral boundary conditions for driving the mesoscale models. The earlier study used the coarse resolution T80L18 ( $\sim 150 \mathrm{~km}$ grid spacing) model forecasts.

- The spatial resolution in two of the mesoscale models, the WRF model and the Eta model, used in the present study are 27 and $32 \mathrm{~km}$ respectively, as against 36 and $48 \mathrm{~km}$ respectively in Das et al (2008).

- The number of vertical levels in the WRF model used in the present study is 38 as against 31 in Das et al (2008).

The RSM mesoscale model used in Das et al (2008) has not been included in the present study. A brief description of the three mesoscale models, the observed and forecast data fields and the analysis methods used in this study are discussed in 


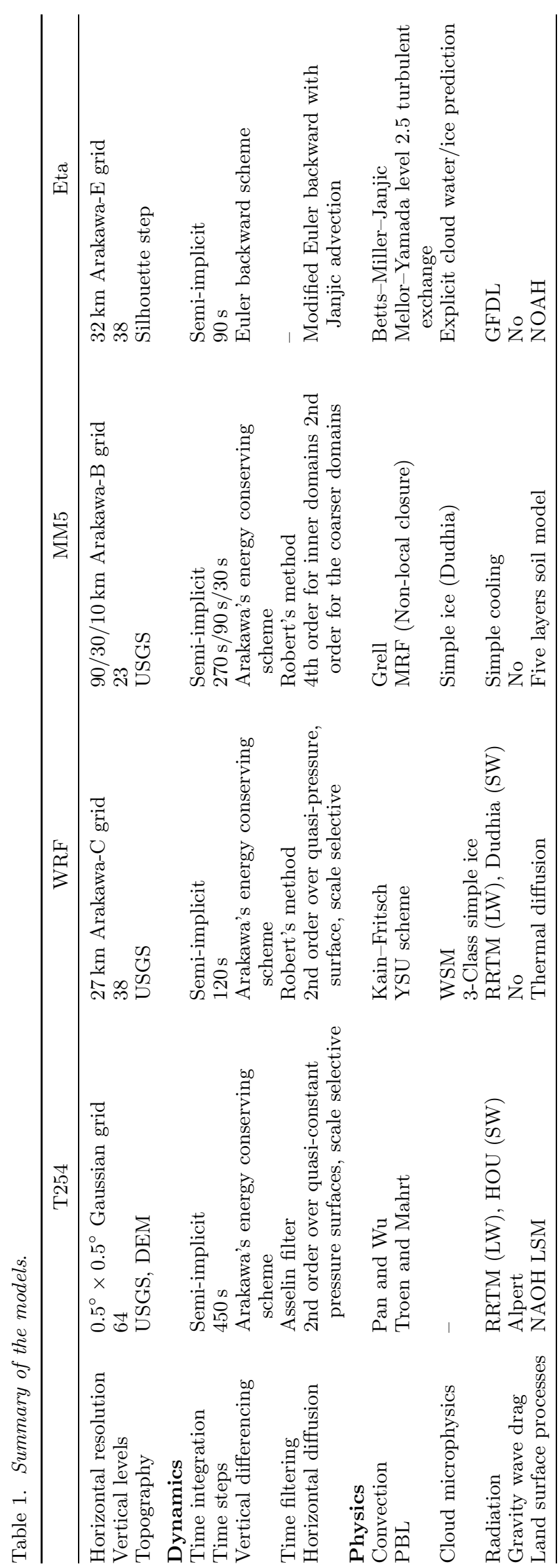

section 2. In section 3 , the description of the observed mean analysis at $850 \mathrm{hPa}$ for wind, temperature and specific humidity are discussed based on the initial analysis gridded on to the respective model resolution. The initial analysis interpolated to respective model grids is discussed in this paper to show that although the initial analysis is obtained from the T254 model, there could be differences in the initial fields due to interpolation techniques, grid staggering, and projection. The T254 Model based initial analysis is subsequently used as a proxy for the actual observations for the forecast verification, since all observed fields are not available at high resolution over India. In section 4 , the predicted seasonal mean characteristics, the systematic errors and the RMSE are discussed. To further examine if the skill and performance of the models in predicting the free atmospheric fields are also reflected in rainfall forecasts, detailed quantitative rainfall forecast verification is presented in section 5. Section 6 provides the summary and conclusions.

\section{Models, data and analysis methods}

\subsection{Operational model details}

A brief description of the configuration of all the four model physics and the dynamics as implemented at NCMRWF is presented in table 1 . The T254 global model features a grid spacing of $0.5 \times 0.5$ degree, whereas mesoscale models, the WRF model and the Eta model have grid spacing of $27 \mathrm{~km}$ and $32 \mathrm{~km}$ respectively. Figure 1 shows the model domains along with the orography (in $\mathrm{km}$ ) at respective model resolution. The MM5 model configuration has triple nested domains at 90, 30 and $10 \mathrm{~km}$ grid spacing. The $10 \mathrm{~km}$ nested grid covers the central Himalayan region (not shown) for mountain weather studies. The two domains shown in figure 1 correspond to mother domain of $90 \mathrm{~km}$ grid spacing and a nested domain of $30 \mathrm{~km}$ grid spacing. The $30 \mathrm{~km}$ domain covers the Indian land region. The analysis presented in this study uses the data from this nested domain. The T254 model has 64 vertical levels, with 38 levels in the WRF and the Eta models and 23 levels in the MM5 model. In the T254 model, the main time integration scheme is the leapfrog scheme for nonlinear advection terms and semi-implicit scheme for gravity waves and for zonal advection of vorticity and moisture. The cumulus parameterization scheme in the T254 model is the Simplified Arakawa-Schubert (SAS) scheme given by Pan and $\mathrm{Wu}$ (1995). The WRF model features the KainFritsch (new Eta) scheme (Kain and Fritsch 1990, 1993). As with the original KF scheme, it utilizes 
(a) MM5

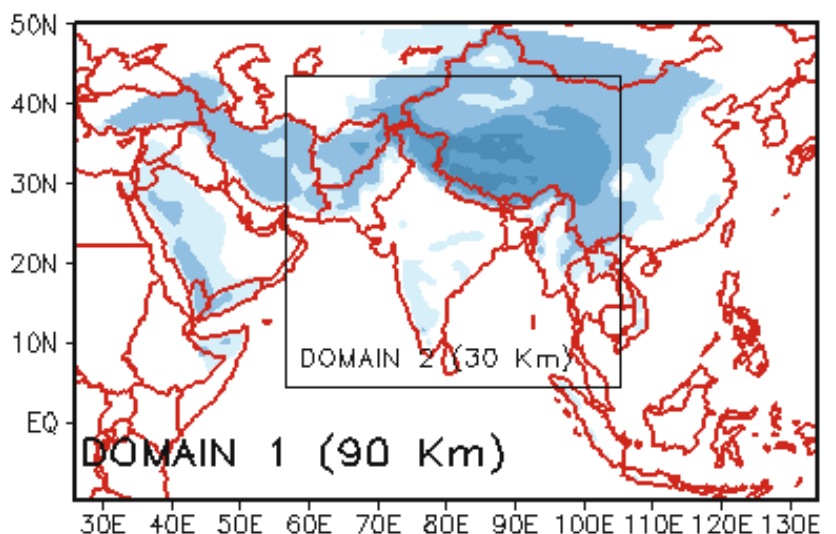

(b) Eta

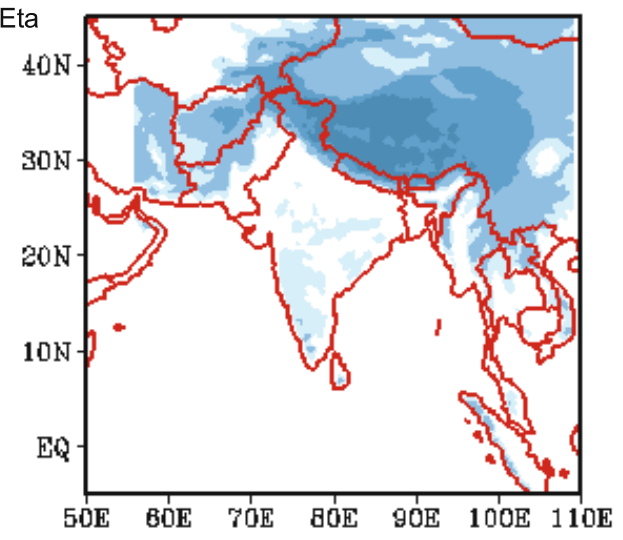

(c) WRF

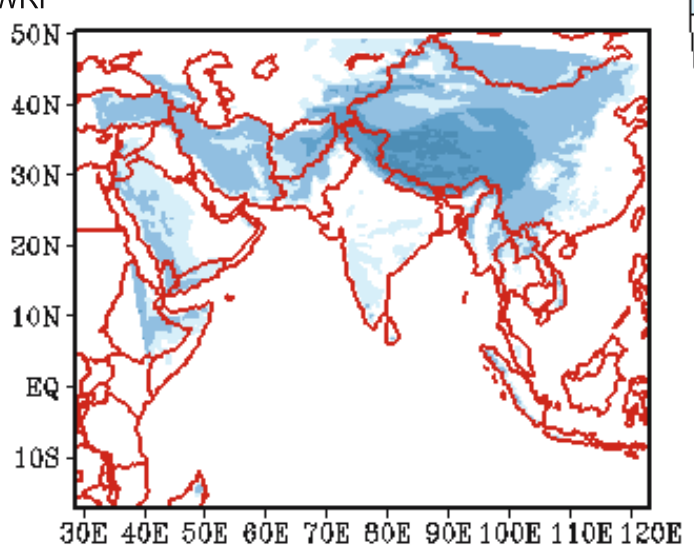

Figure 1. Domains of the mesoscale models with orography at model resolution.

a simple cloud model with moist updrafts and downdrafts, including the effects of detrainment, entrainment, and relatively simple microphysics. The MM5 model uses the Grell's scheme (Grell et al 1991) for cumulus parameterization. It is a simple single-cloud scheme with updraft and downdraft fluxes and compensating motion determining heating/moistening profile. This scheme is useful for smaller grid sizes $10-30 \mathrm{~km}$. It tends to allow a balance between resolved scale rainfall and convective rainfall. The shear effects on precipitation efficiency are also considered. For details, readers may refer Grell et al (1994). The Eta model has the Betts-Miller-Janjic scheme (Janjic 1994, 2000) for cumulus parameterization. This scheme adjusts the grid-column sounding towards a reference sounding (convective adjustment to a reference post-convective thermodynamic profile over a given period). This scheme is suitable for resolution greater than $30 \mathrm{~km}$, but it has no explicit downdraft, so it may not be suitable for severe convection. Rajagopal and Iyengar $(2002,2005)$ provide a description of the Eta model implementation at NCMRWF.

\subsection{Data and analysis method}

The standard verification methods for predicted free atmospheric fields involve computation of (i) the systematic errors and (ii) RMSE. The systematic errors in the day-3 forecast winds $(u, v)$, temperature and specific humidity at $850 \mathrm{hPa}$ are discussed. The systematic error is actually the average of forecast errors (forecast - observation) computed for each day. Thus it is actually the mean error (ME) chosen to represent the systematic error. The RMSE is computed for day- 1 , day- 2 and day-3 forecasts at 1000, 925, 850, 700 500, 400 300 and $200 \mathrm{hPa}$ for five fields:

- geopotential height,

- temperature,

- zonal wind,

- meridional wind, and

- specific humidity.

Forecast errors are computed relative to the T254 model initial analysis. For detailed and quantitative rainfall forecast verification, we use the $0.5^{\circ}$ daily rainfall analysis developed by the India Meteorological Department (IMD) (Rajeevan et al 2005; Rajeevan and Bhate 2008). This is the high-resolution daily gridded rainfall dataset useful for the mesoscale meteorological studies. The daily rainfall data from the four models is gridded on to the observed rainfall grids over Indian land regions for the 122 days from 1 June through 30 September 2008. A series of statistical scores are computed based on a categorical contingency table (table 2) whereby an event ('yes') is defined by rainfall greater than or equal to the specified threshold $(0.5 \mathrm{~cm} /$ day $)$; otherwise, it is a nonevent ('no'). The table 3 gives a detailed list of nine statistical scores applied for rainfall forecast verification. We have chosen the forecast skill scores based on the World Meteorological Organization (WMO) World Weather Research Programme (WWRP) recommendations given in WWRP 2009-1 (2009). We have given detailed 
Table 2. Contingency table for categorical forecasts of a binary event. Here $a, b, c$ and $d$ are the number of events observed to occur above a threshold.

\begin{tabular}{|c|c|c|c|}
\hline \multirow[b]{2}{*}{ Forecast } & \multicolumn{2}{|r|}{ Observed } & \multirow[b]{2}{*}{ Total } \\
\hline & Yes & No & \\
\hline Yes & $\begin{array}{c}a \\
\text { (hit) }\end{array}$ & $\begin{array}{c}b \\
\text { (false alarm) }\end{array}$ & $a+b$ \\
\hline No & $\begin{array}{c}c \\
\text { (miss) }\end{array}$ & $\begin{array}{c}d \\
\text { (correct rejection) }\end{array}$ & $c+d$ \\
\hline Total & $a+c$ & $b+d$ & $a+b+c+d=n$ \\
\hline
\end{tabular}

description of these skill scores in table 3 and as and where discussed.

\section{Mean analysis}

In this section we present the seasonal (JJAS 2008) mean analysis of wind, temperature and specific humidity at $850 \mathrm{hPa}$ level. Since the NCMRWF T254 global model analysis provides the initial conditions for the three mesoscale models (WRF, MM5, and Eta), the basic circulation characteristics of the initial conditions are expected to remain the same in all the models. Minor differences may occur after interpolations to the model domains due to the differences in their resolutions, map projections, and domain size. The mesoscale models feature three different types of staggered grids as shown in table 1 .

\subsection{Mean monsoon circulation: $850 \mathrm{hPa}$ winds}

The Cross-Equatorial Flow (CEF) is one of the characteristic features of low-level monsoon circulation that stands out as the strongest low-level flow on the earth during the boreal (northern) summer. The wind speed in the core of the Somali Jet exceeds $25 \mathrm{~m} \mathrm{~s}^{-1}$ (Findlater 1969); the jet core is located about $1.5 \mathrm{~km}$ above sea level, 200 $400 \mathrm{~km}$ east of the east African highlands. This $\mathrm{CEF}$ is an essential component of the Asian monsoon system. It transports the moisture from the southern Indian Ocean to South Asia, connects the Mascarene high and Indian monsoon trough, and completes the lower branch of the Hadley cell of the Asian monsoon.

The four panels in figure 2 show the seasonal mean (JJAS) winds $\left(\mathrm{m} \mathrm{s}^{-1}\right)$ and the geopotential height $(\mathrm{m})$ in the initial condition at $850 \mathrm{hPa}$. Shading in the figure indicates magnitude of the zonal component of wind $\left(\mathrm{m} \mathrm{s}^{-1}\right)$ with westerlies (positive) in blue and easterly component (negative) in yellow and red. The panels corresponding to all four models indicate that the analysis captures the basic circulation characteristics, i.e., southwesterly flow over the Arabian Sea at $850 \mathrm{hPa}$ fairly well. The flow crosses the Indian peninsula and turn towards the Indo-Gangetic plains over the head Bay of Bengal. This feature is prominent in all the models. The zonal wind speed reaches up to $15-20 \mathrm{~m} \mathrm{~s}^{-1}$ in a narrow band over the western Arabian Sea, which is a typical characteristic of the Somali Jet. Although the MM5 model domain size is too small to cover the southwesterly flow close to African coast, near the west coast of India and over the Indian peninsula, the MM5 model shows strong zonal winds in the range of $10-15 \mathrm{~m} \mathrm{~s}^{-1}$. The WRF and Eta models also show comparable magnitudes. As can be seen in figure 2, the model analysis shows well captured monsoon trough in the initial conditions in the form of a narrow trough extending from northwest of India to the head Bay of Bengal.

\subsection{Mean temperature at $850 \mathrm{hPa}$}

The monsoon circulation over the South Asia is very intense, essentially due to high and extensive Himalayan-Tibetan highland with input of diabatic heating over large area in the middle troposphere oriented in nearly east-west direction. To the south of India lies extensive mass of Indian Ocean waters. During the northern summer season, this configuration of landmass and watermass creates strong meridional temperature gradient leading to flow of air from cool oceanic area to warm land area. Accurate representation of the observed land-sea temperature contrast and its evolution in the model initial analysis is crucial for predicting the onset and advance of the monsoon over India. The seasonal mean (JJAS 2008) temperature distribution at $850 \mathrm{hPa}$ in the initial conditions (analysis) is shown in figure 3 . All the four models indicate a north-south temperature gradient over the Indian land region with a maximum of about $24^{\circ} \mathrm{C}$ over the north-west India. However, over adjoining Pakistan region, still higher temperatures of up to $30^{\circ} \mathrm{C}$ persist over the PakistanAfghanistan region. Over central India and the peninsula, the mean temperatures are generally over $20^{\circ} \mathrm{C}$ in all the models. During June and July (not shown) the models indicate a strong northsouth temperature gradient with a maximum of about $26^{\circ} \mathrm{C}$ at $850 \mathrm{hPa}$ over the north-west India and adjoining Pakistan region. The heating further increases with highest temperature of about $32^{\circ} \mathrm{C}$ over the Pakistan-Afghanistan region producing a heat low in the lower troposphere during these months. The heating reduces in the month of August (figure not shown) after the complete onset of monsoon over north-west India and adjoining Pakistan region. It decreases further to a 
Table 3. Forecast verification statistics used for evaluating the mesoscale model rainfall forecasts during monsoon 2008.

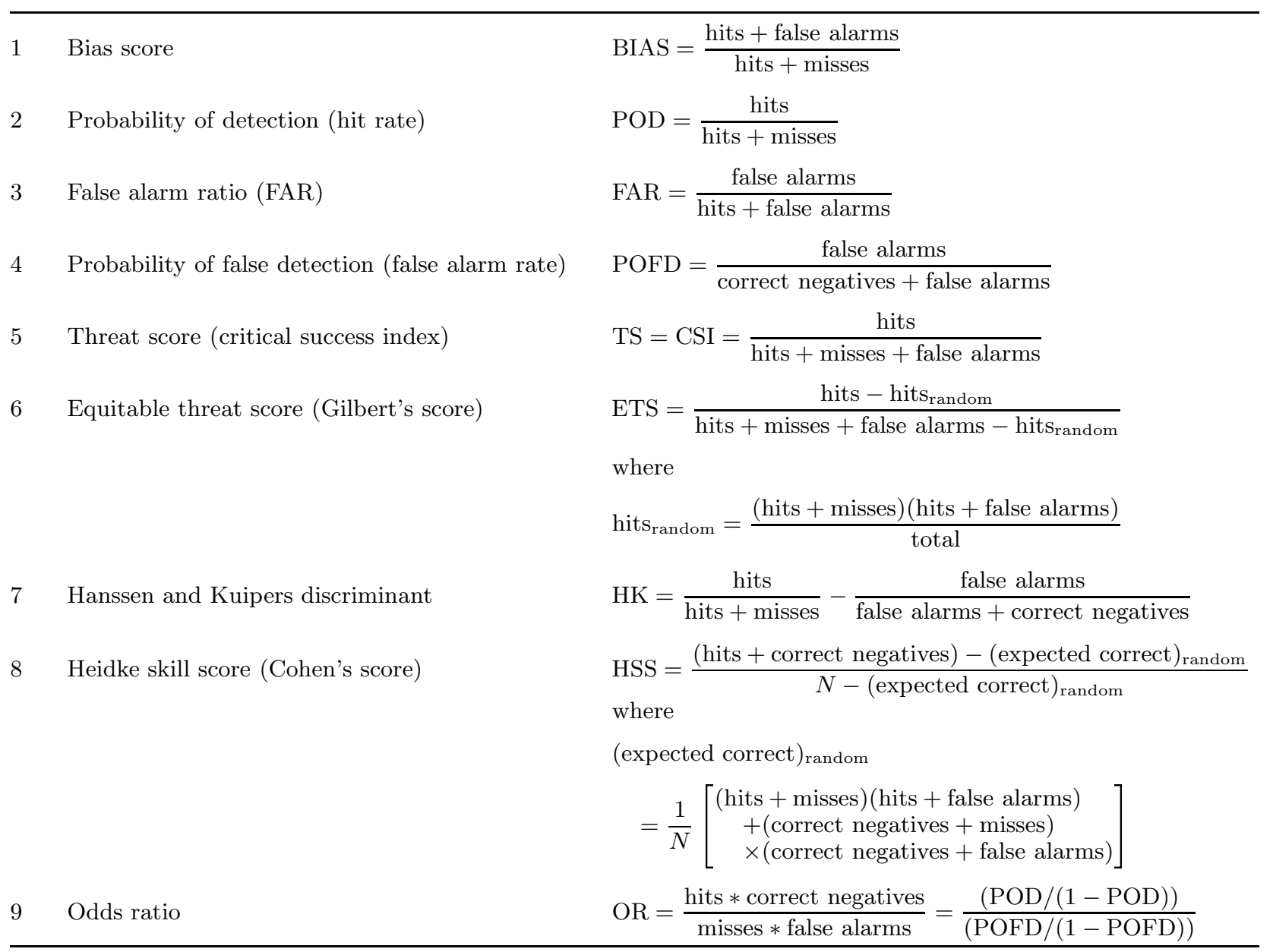

value of $22^{\circ} \mathrm{C}$ in the month of September. Three models namely T254, WRF, Eta showed a highest temperature of $28^{\circ} \mathrm{C}$ over the Pakistan region, but MM5 showed a maximum of only up to $26^{\circ} \mathrm{C}$ over the above said region.

The models capture the sharp north-south temperature gradient with peak in the month of July and subsequently reduction in the gradient in the month of September. Over central India and the peninsula, the mean JJAS temperatures are generally more than $20^{\circ} \mathrm{C}$ in all the models.

\subsection{Mean specific humidity at $850 \mathrm{hPa}$}

This section gives a discussion on the mean conditions of moisture distribution in the initial analysis. The Asian summer monsoon plays a crucial role in moisture transport. The most remarkable moisture channel originates in the southern Indian Ocean, crossing the equator near the Somali coastal region, flowing to the Arabian Sea and the Bay of Bengal.

The figure 4 shows the JJAS mean analysis of specific humidity $\left(\mathrm{g} \mathrm{kg}^{-1}\right)$ at $850 \mathrm{hPa}$ for the four models. Specific humidity values exceeding
$12 \mathrm{~g} \mathrm{~kg}^{-1}$ cover large area over the Indian land region and Bay of Bengal. The Arabian Sea and Indian Ocean feature relatively lower specific humidity. High values of specific humidity seen over the Indo-Gangetic basin (excess of $14 \mathrm{~g} \mathrm{~kg}^{-1}$ ) are manifestation of the monsoon trough and the associated convection in that region. The high moisture in this region seen in the seasonal mean can be associated with the monsoon depression that travels along the monsoon trough. The figure 4 indicates that the Eta model shows specific humidity distribution of high value (excess of $14 \mathrm{~g} \mathrm{~kg}^{-1}$ ) over a larger area (southward of monsoon trough region) compared to both the WRF and the MM5 model. It is interesting to note that, over parts of the Arabian Sea, the Eta model features lower values of specific humidity compared to the WRF and the MM5 models. Each of the months of JJAS 2008, show this particular feature of the Eta model (not shown). However, the moisture decreases in the month of September with the weakening of the monsoon. Even in September, the Eta model is relatively moisterous than the other three models particularly over the northeastern region and north Bay of Bengal. 
ANALYSIS:Mean Winds (m/s) \& Geop. Ht. (m) at $850 \mathrm{hPa}$ for JJAS, 08
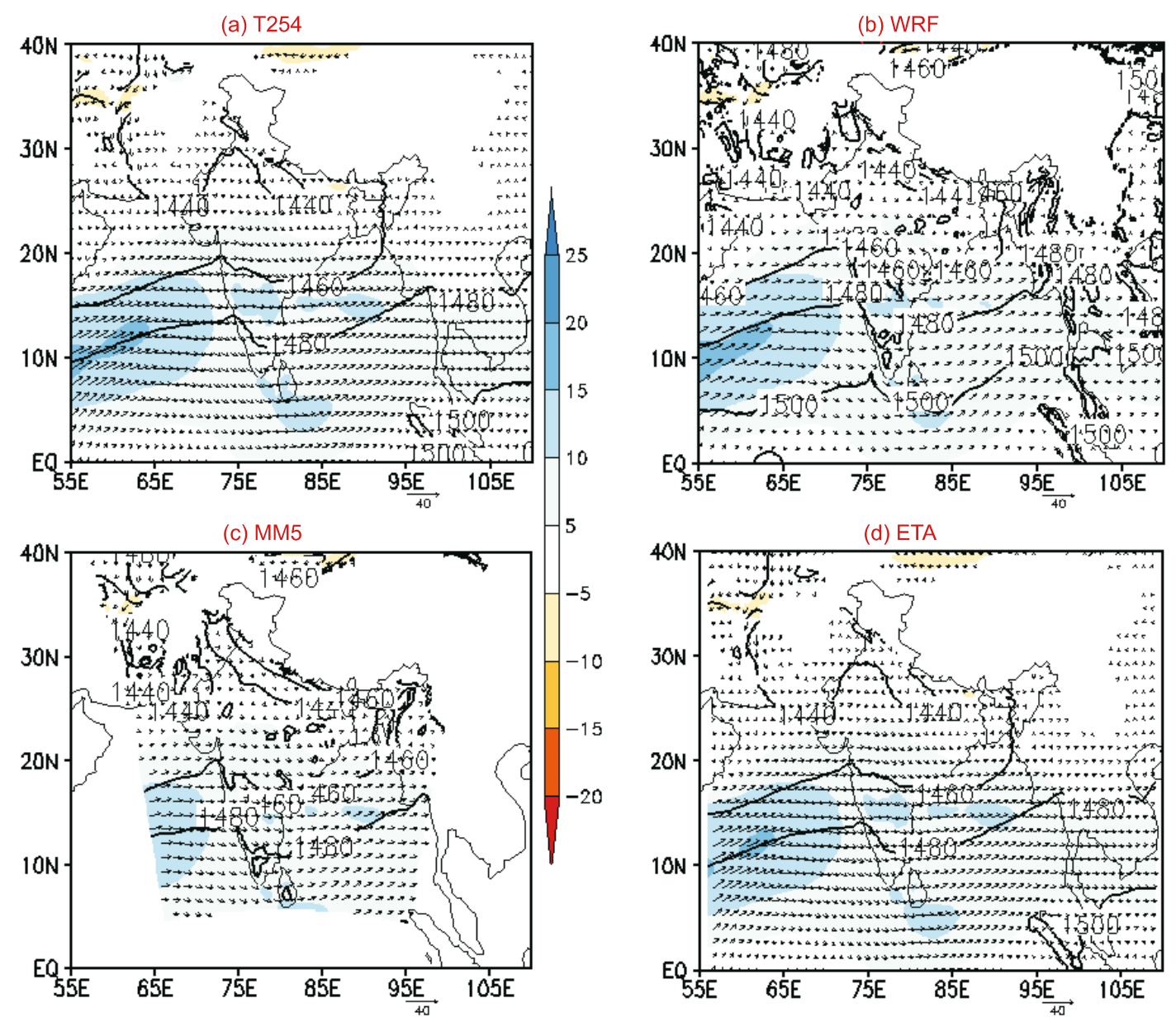

(d) ETA

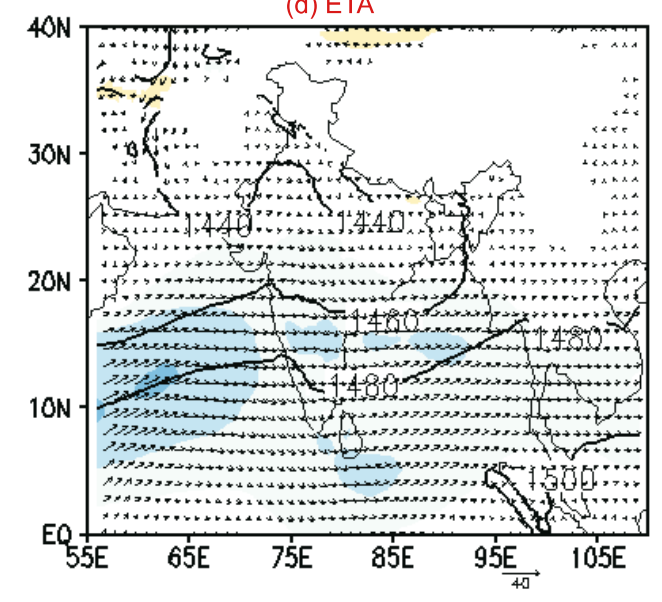

Figure 2. Mean analysis of $850 \mathrm{hPa}$ winds and geopotentials for JJAS 2008 interpolated from T254 global model to the respective grids of (a) T254, (b) WRF, (c) MM5, and (d) Eta. Shading indicates magnitude of zonal wind (m s ${ }^{-1}$ ).

\section{Forecast mean characteristics and the systematic errors}

Here we present the seasonal mean circulation, temperature and specific humidity distribution at $850 \mathrm{hPa}$ based on the day-3 forecasts. The model forecast errors expressed in terms of the systematic errors in this section, aim to provide a qualitative description of the spatial distribution of errors. Further, the RMSE at different vertical levels quantify the model errors. The RMSE is a kind of generalized standard deviation. Also called the root mean square deviation (RMSD) the RMSE is frequently used measure of the differences between the values predicted by a model and the values actually observed. It is a good measure of the accuracy of forecast.

\subsection{Wind at $850 \mathrm{hPa}$}

The four panels in figure 5 show the seasonal (JJAS) mean day-3 forecast wind $\left(\mathrm{m} \mathrm{s}^{-1}\right)$ and geopotential height $(\mathrm{m})$ at $850 \mathrm{hPa}$. The predicted basic circulation matches with the analysis shown in figure 2. The southwesterly flow over the Arabian Sea crosses the Indian peninsula and turns towards the Indo-Gangetic plains over the head Bay of Bengal in the model predictions. The predicted circulation is realistic compared to the mean analysis discussed in figure 2 . The zonal wind speed reaches up to $15-20 \mathrm{~m} \mathrm{~s}^{-1}$ (blue) over the western Arabian Sea, which is a typical characteristic of the Somali Jet. Predicted flow seems to be slightly south of the flow in the analysis. The WRF model shows weak flow over the western Arabian Sea in the day-3 forecast compared to that in Eta as well as the global model. However, the predicted monsoon trough is rather weak and broad compared to the trough in the analysis discussed in figure 2 .

The panels in figure 6 show the systematic errors in the day-3 forecast wind fields $\left(\mathrm{m} \mathrm{s}^{-1}\right)$ for JJAS at $850 \mathrm{hPa}$ for the four models. The shading in the figure indicates errors in the magnitude of the zonal wind $\left(\mathrm{m} \mathrm{s}^{-1}\right)$ (positive error in blue and 

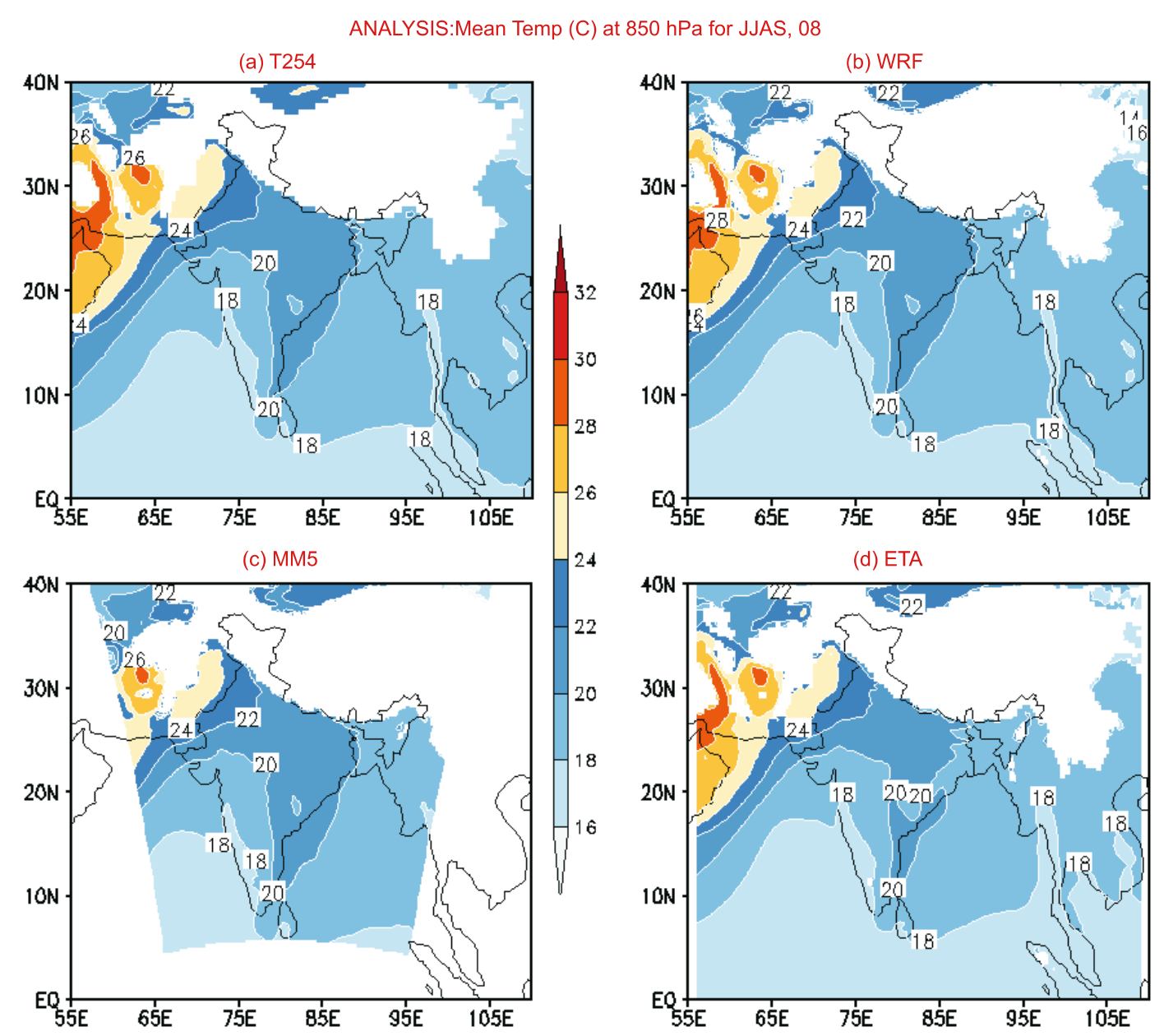

Figure 3. As in figure 2 for temperature ${ }^{\circ} \mathrm{C}$ at $850 \mathrm{hPa}$.

negative error in yellow to red). The systematic error in the $850 \mathrm{hPa}$ wind in the $\mathrm{WRF}$ and the MM5 model forecasts show easterly bias over the large parts of Arabian Sea. This feature suggests a weak $\mathrm{CEF}$ in the day-3 forecasts. The systematic error in the Eta model forecasts features westerly bias (with a maximum up to $8 \mathrm{~m} \mathrm{~s}^{-1}$ ) over south peninsular India. The magnitude of the systematic error in the T254 model is smaller than the errors in the mesoscale models. The WRF and MM5 model forecasts feature weaker (than analysis) winds to the north and stronger (than analysis) winds to the south over the Arabian Sea. The day- 1 and day- 2 forecasts also show these features (not shown). However, the magnitude of errors is large in the day-3 forecasts by $4 \mathrm{~m} \mathrm{~s}^{-1}$. While it would be difficult to establish, a significant part of the errors could be due to the boundary conditions. Over the land regions, westerly bias over the south peninsula and easterly bias over central India is prominent in all the forecasts. In the Eta model forecasts large part of peninsula feature westerly bias suggesting strong westerly flow in the forecasts.

\subsection{Temperature at $850 \mathrm{hPa}$}

The seasonal (JJAS 2008) mean $850 \mathrm{hPa}$ temperature distribution in the day- 3 forecast is shown in figure 7. A comparison with the $850 \mathrm{hPa}$ temperature distribution in the analysis shown in figure 2 suggest that the forecasts underestimate the $850 \mathrm{hPa}$ temperature in all the models. All the four models indicate a north-south temperature gradient over the Indian region with a maximum of about $24^{\circ} \mathrm{C}$ at $850 \mathrm{hPa}$ over the north-west India and adjoining Pakistan region (higher temperatures of up to $30^{\circ} \mathrm{C}$ persists over the PakistanAfghanistan region). The Eta model forecasts are similar to that of the T254 model with temperatures in the range of $20-24^{\circ} \mathrm{C}$ covering parts of northwest India. The temperature decreases southwards (rather sharply) and eastwards. The WRF model forecasts feature rather warmer temperatures over the land and the MM5 model forecasts indicate cooler temperature compared to the T254 model and the Eta model.

The systematic errors in the $850 \mathrm{hPa}$ temperature $\left({ }^{\circ} \mathrm{C}\right)$ for the four models forecasts are shown 

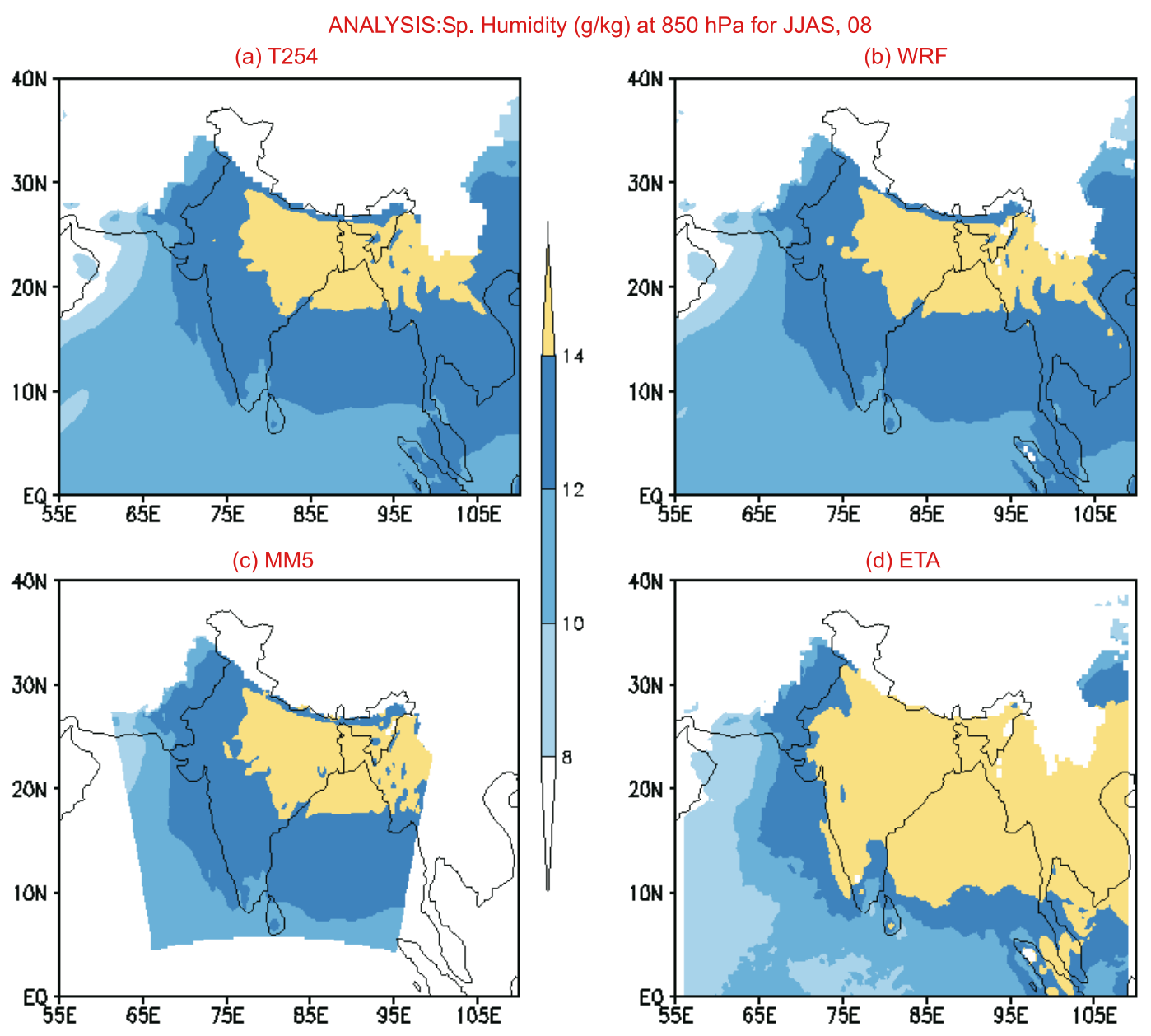

Figure 4. As in figure 2 for specific humidity $\left(\mathrm{g} \mathrm{kg}^{-1}\right)$ at $850 \mathrm{hPa}$.

in figure 8. All the models (except the MM5 model) overpredicted the temperature over northwest India and adjoining Pakistan region. Except the WRF model, all the models underpredicted the temperature over south peninsula. The MM5 model underpredicted the temperatures all over the Indian region. This figure indicates that the MM5 model produces cold bias all over India, and Indian Ocean with a peak bias of up to $3^{\circ} \mathrm{C}$ over the Bay of Bengal adjoining to the east coast of south peninsular, and Pakistan-Afghanistan region. The day-1 and day-2 forecasts (not shown) also typically show this feature. The T254, WRF, and Eta models showed a warm bias over the northwest India and adjoining Pakistan-Afghanistan region with a peak bias of up to $3^{\circ} \mathrm{C}$ in the Eta model and the WRF model forecasts. The WRF model showed warm bias extending over the northern Arabian Sea (up to $2^{\circ} \mathrm{C}$ ). The T254 model and the Eta model showed a cold bias along few places over the south peninsular India, and the Eta model showed cold bias over the west Arabian Sea.

\subsection{Specific humidity at $850 \mathrm{hPa}$}

The seasonal (JJAS 2008) mean $850 \mathrm{hPa}$ specific humidity $\left(\mathrm{g} \mathrm{kg}^{-1}\right)$ distribution in the day-3 forecasts is shown in figure 9 . The figure shows the area with specific humidity greater than $12 \mathrm{~g} \mathrm{~kg}^{-1}$ covering the Indian land region and parts of the Bay of Bengal. The Arabian Sea and Indian Ocean feature relatively lower value of specific humidity. Over the land, the Indo-Gangetic basin features high values of specific humidity (greater than $14 \mathrm{~g} \mathrm{~kg}^{-1}$ ). This is the region of the monsoon trough and the monsoon depressions that travels along the monsoon trough causing deep convection in that region can explain the high values of specific humidity in that region.

Figure 10 shows the systematic errors in the specific humidity $\left(\mathrm{g} \mathrm{kg}^{-1}\right)$ forecasts. This figure indicates that the Eta model and the WRF model have similar systematic errors in the predicted specific humidity distribution over the north-west India and the Arabian Sea. The Eta model features dry bias over the Bay of Bengal with maximum 
DAY-3 FCST:Mean Winds (m/s) \& Geop. Ht.(m) at $850 \mathrm{hPa}$ for JJAS, 08
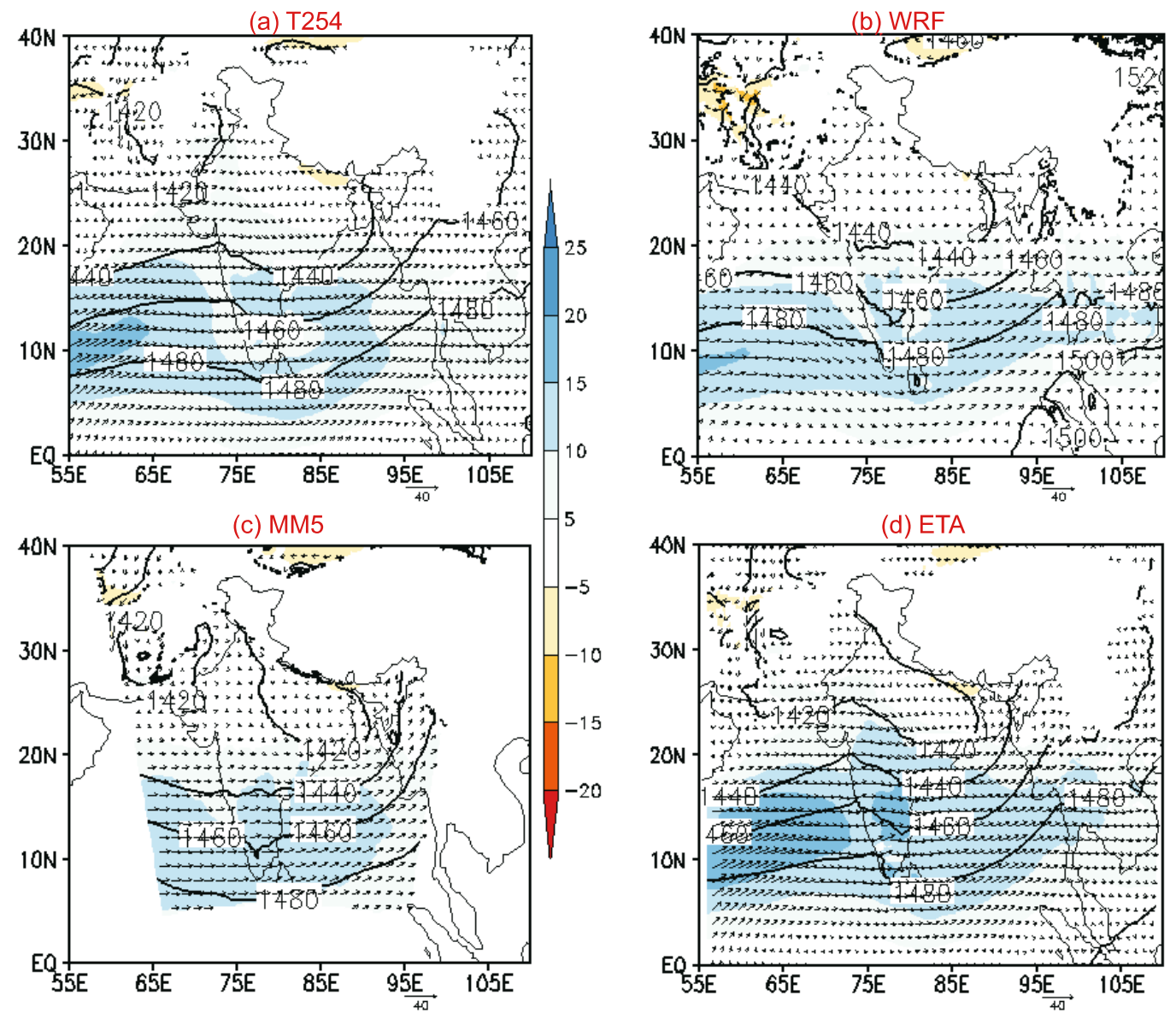

Figure 5. Mean day-3 forecast of $850 \mathrm{hPa}$ winds and geopotential for JJAS 2008 in (a) T254, (b) WRF, (c) MM5, and (d) Eta. Shading indicates magnitude of zonal wind $\left(\mathrm{m} \mathrm{s}^{-1}\right)$.

bias up to $4 \mathrm{~g} \mathrm{~kg}^{-1}$ (also in the day-1 forecast (figure not shown)), while the MM5 model produced moist bias (up to $2 \mathrm{~g} \mathrm{~kg}^{-1}$ ). The WRF and the Eta models feature dry bias over the northern Arabian Sea and adjoining Pakistan-Afghanistan region (up to $3 \mathrm{~g} \mathrm{~kg}^{-1}$ ), the T254 model also showed dry bias over the Pakistan-Afghanistan region only. All the models produce moist bias over the northeastern India (up to $3 \mathrm{~g} \mathrm{~kg}^{-1}$ ). The MM5 and Eta models show moist bias along the west coast up to $2 \mathrm{~g} \mathrm{~kg}^{-1}$. All the models showed no errors over most of the Indian land. The patterns of errors in the day- 3 forecasts are similar to the day-1 forecast errors except for the higher magnitude of errors in the day-3 forecast by $1-2 \mathrm{~g} \mathrm{~kg}^{-1}$.

\subsection{The RMSE}

The RMSE gives the average magnitude of the forecast error. While it does not indicate the direction of the deviations, it puts greater influence on large errors than smaller errors. The RMSE of day-1, day-2 and day-3 forecasts (rows 1-3) for geopotential heights, temperature $(T)$, zonal and meridional winds $(U, V)$ and specific humidity $(q)$ (columns 1-5) at different vertical levels are shown in figure 11. The RMSEs have been computed over the Indian region $\left(8^{\circ}-38^{\circ} \mathrm{N} / 68^{\circ}-98^{\circ} \mathrm{E}\right)$ relative to the T254 model analysis. The RMSE in geopotential height (first column) for the day1, day-2 and day-3 forecasts show that the WRF model features least errors on all days compared to other two models. While all the three models show a general increase in the magnitude of error with height, the MM5 model features rather sharp increase in the RMSE with height. Similarly for the temperatures (column 2), the RMSE at different levels are given for day-1, day-2 and day-3 forecasts. The WRF model shows the least error and the MM5 model features the largest error in the lower levels below $700 \mathrm{hPa}$. Above the $700 \mathrm{hPa}$ level, the errors range between $1^{\circ}$ and $2.5^{\circ} \mathrm{C}$ in all the models and all the forecasts, the Eta model featuring lowest error (between $700 \mathrm{hPa}$ and $400 \mathrm{hPa}$ levels) particularly in day- 2 and day3 forecasts. The columns 3 and 4 in figure 11 show the RMSE in $U$ and $V$. Different models show least error at different levels. For example, the WRF 


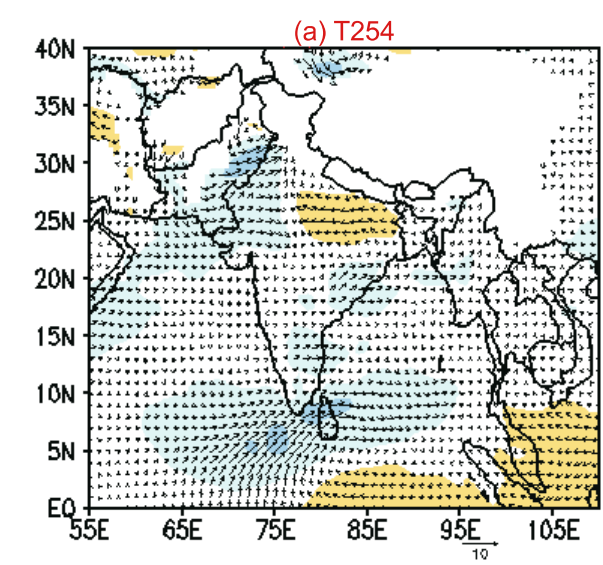

(c) MM5

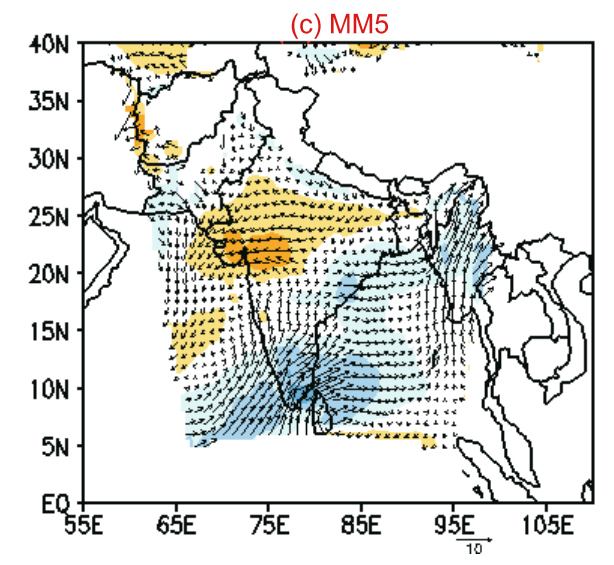

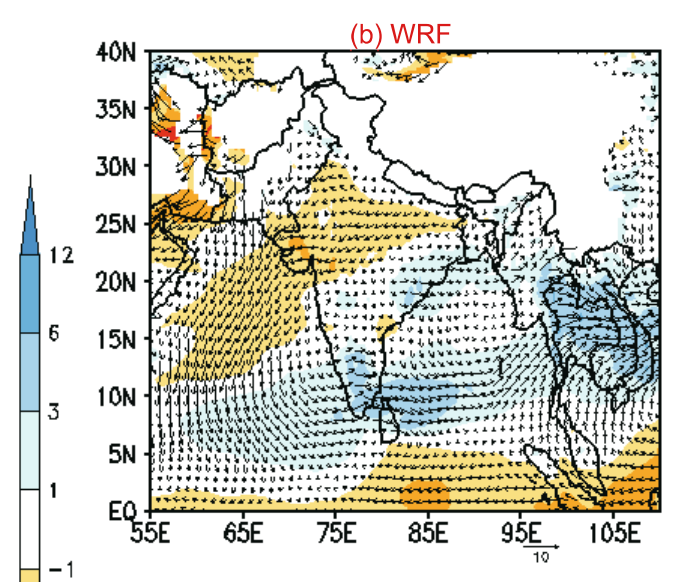

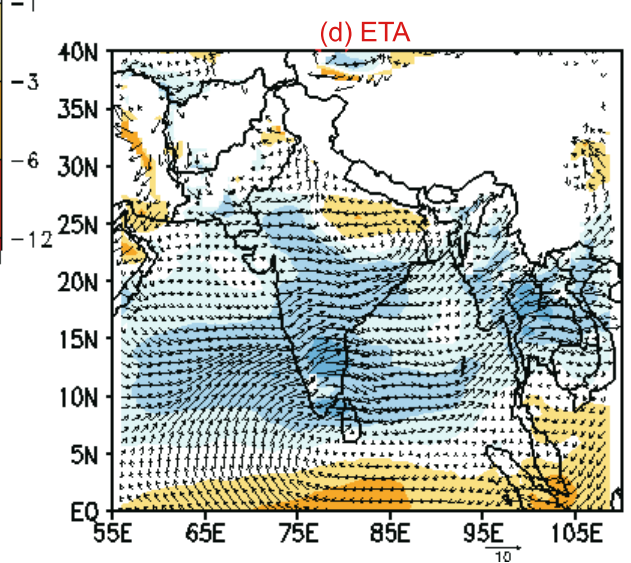

Figure 6. Systematic errors of $850 \mathrm{hPa}$ winds $\left(\mathrm{m} \mathrm{s}^{-1}\right)$ in the day-3 forecasts of JJAS in (a) T254, (b) WRF, (c) MM5, and (d) Eta. Shading indicates errors in zonal of wind $\left(\mathrm{m} \mathrm{s}^{-1}\right)$.

model features least RMSE in the day- 1 forecast $U$ and $V$ above $700 \mathrm{hPa}$ level. In the day-2 forecast, the Eta model features least RMSE above $700 \mathrm{hPa}$. The RMSE for specific humidity (column 5) shows that the WRF model features the least error at all levels. All the models show decreasing magnitude of errors above $400 \mathrm{hPa}$ mainly due to reduced moisture at higher altitudes.

Thus, the RMSE analysis involving the free atmospheric fields clearly indicates that WRF model forecasts feature least errors in the forecast geopotential height, specific humidity at all vertical levels, and the temperature below $700 \mathrm{hPa}$. It would be interesting to see if the rainfall forecasts of the mesoscale models also feature similar skill seen in predicting the circulation, temperature, and humidity fields.

\section{Rainfall forecast during monsoon 2008}

The rainfall during the monsoon season accounts for about $78 \%$ of the annual rainfall averaged over India (Pant and Rupa Kumar 1997). The rainfall averaged over the homogenous southern peninsular of India contributes by only about $60 \%$ to the annual mean, and a significant amount (nearly $30 \%$ of the annual) also occurs in the post-monsoon season or the north-east monsoon rainy season. For annual as well as monsoon season rainfall, the two prominent high rainfall pockets dominate the mean rainfall distribution mainly due to the orographic effects. These are the rainfall (i) off the west coast of India and (ii) along the northeast India and foothills of the sub-Himalayan ranges. There is a general decrease of rainfall amounts from east to west in central India and along the Gangetic Plains. The mean rainfall over the arid regions of west Rajasthan, Saurashtra, and Kutch is less than one-third over the Gangetic West Bengal. The monsoon season features intraseasonal variations in the rainfall amount and distribution. The active and weak cycles in the monsoon and the Bay of Bengal lowpressure systems that move inland causing heavy rainfall over land regions largely determine the rainfall amount and distribution.

\subsection{Mean monsoon rainfall during JJAS 2008}

Mesoscale models with high spatial resolution attempt to capture the mesoscale processes in the 


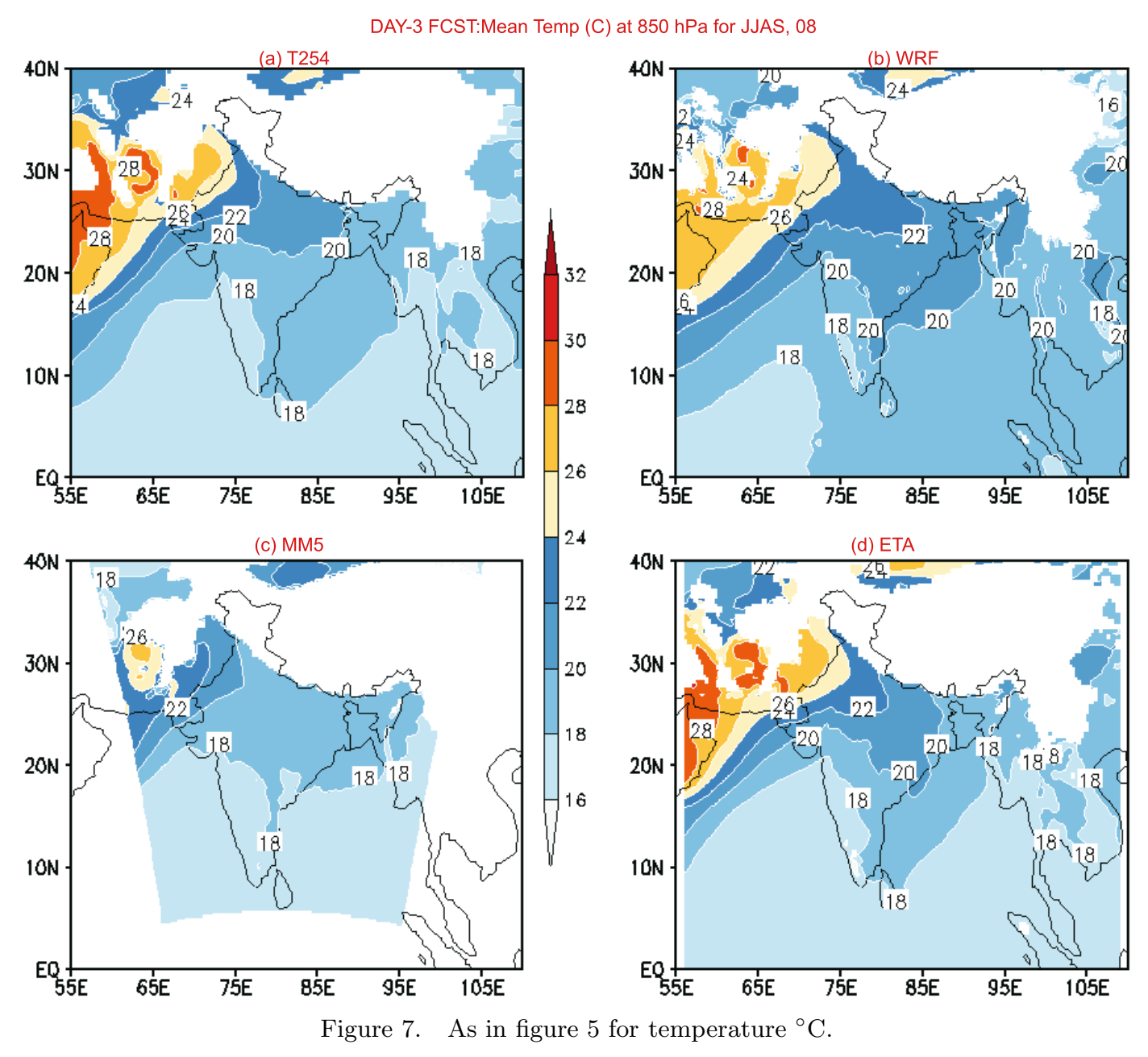

storms and try to provide a better rainfall prediction compared to the coarse resolution global models. Evaluation is carried out for day-1, day-2 and day- 3 forecasts of rainfall using $0.5^{\circ}$ daily rainfall data of IMD described in section 2 .

The figure 12 shows the observed and the day-3 forecasts of rainfall $(\mathrm{cm} /$ day) averaged over the monsoon season. The observed distribution of rainfall indicates the maximum rainfall of up to $2 \mathrm{~cm} /$ day along the west coast of India surrounded by rainfall in the range of $1-2 \mathrm{~cm} /$ day. Similar rainfall amounts in the range of $1-2 \mathrm{~cm} /$ day are also prominent over parts of northeast India, Gangetic Plains and large region covering the West Bengal and Orissa. Over the west coast and the parts of northeastern India, the model forecasts show mean rainfall excess of $4 \mathrm{~cm} /$ day at many locations surrounded by rainfall in the range of $1-2 \mathrm{~cm} /$ day. The day-3 forecasts clearly overestimated the rainfall over these two regions. The day- 1 and day- 2 forecasts (not shown) also show overestimated rainfall. The rainfall over the Gangetic Plains is underestimated $(0.5-1 \mathrm{~cm} /$ day; even lesser in Eta) in all the forecasts. The central India features overestimated rainfall in all the three models. This is particularly prominent in Eta model forecast with rainfall in the range of $2-4 \mathrm{~cm} /$ day.

\subsection{Rainfall forecast verification}

Detailed and quantitative rainfall forecast verification is presented in this section using the gridded $0.5^{\circ}$ daily rainfall data of IMD, for the entire period of JJAS 2008. The daily rainfall data from the four models is gridded on to the observed rainfall grids over Indian land regions for the 122 days from 1 June through 30 September, 2008. Firstly, the mean differences in the observed and the model predicted rainfall is discussed followed by detailed analysis based on the skill scores. The table 2 shows the contingency table for categorical forecasts of a binary event used to compute the statistical skill scores. The computations take into account only the rainy days, i.e., days with rainfall amounts equal to or more than $0.5 \mathrm{~cm}$ at each grid over land regions.

\subsubsection{Forecast rainfall differences}

The earlier discussion in section 5.1 clearly indicated a tendency of the models to overestimate 
(a) T254

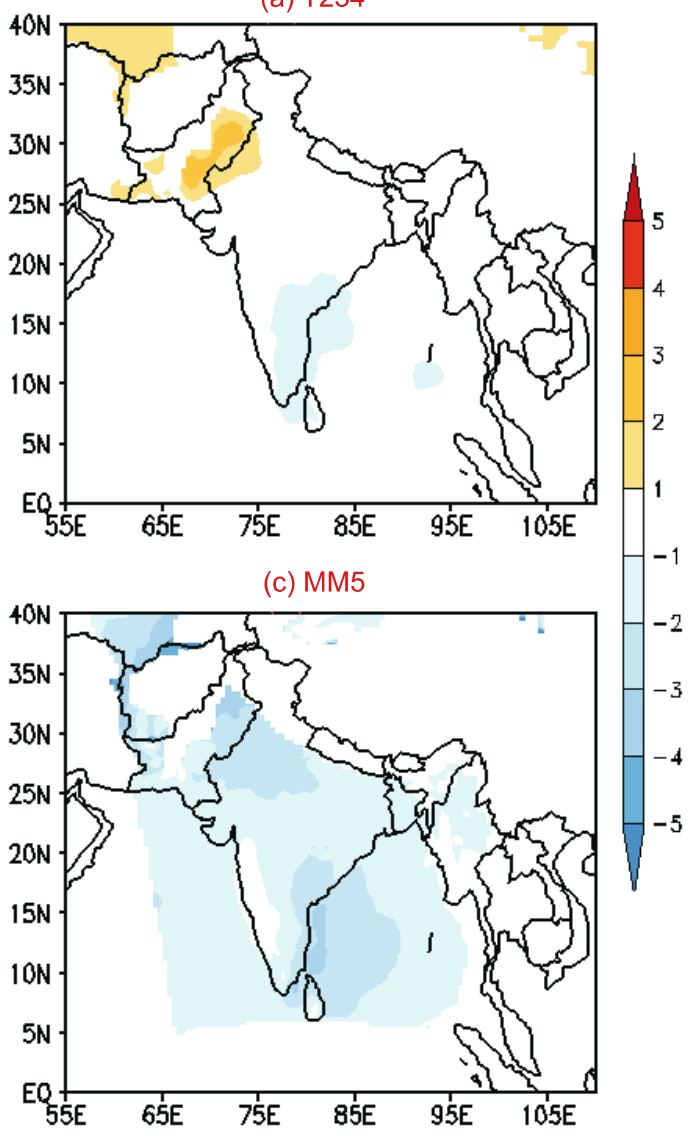

(b) WRF

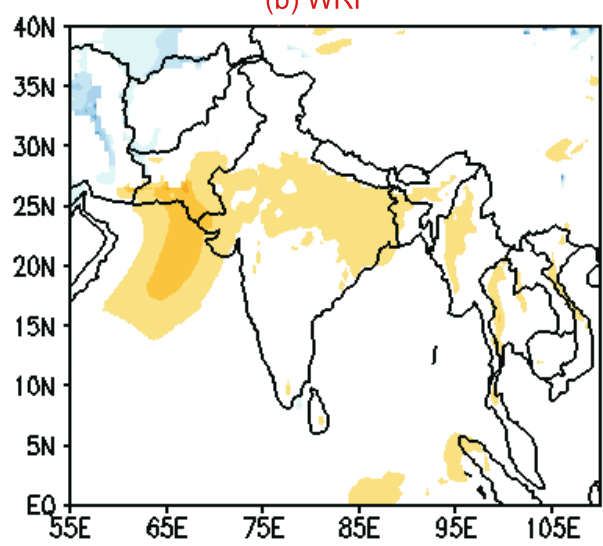

(d) ETA

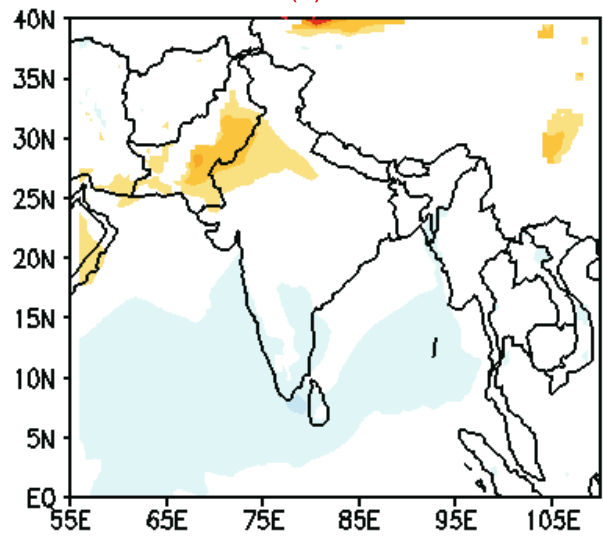

Figure 8. As in figure 6 for temperature ${ }^{\circ} \mathrm{C}$.

the mean JJAS rainfall over the west coast and northeastern parts of India and underestimate the mean JJAS rainfall over the Gangetic Plains. The differences in the observed and forecast rainfall, for day-1, day-2 and day-3 forecasts (columns 1, 2 and 3 ) for the WRF, MM5 and Eta models (rows 1,2 and 3 ) are shown in figure 13 . The WRF model typically features underestimated rainfall by about $2 \mathrm{~cm} /$ day all along the foothills of Himalayas from west to east in all the three forecasts. Similarly, over the eastern peninsula the mean rainfall is underpredicted by about 0.5 to $1 \mathrm{~cm} /$ day. These two features are also seen in the Eta model forecasts (bottom panels) with higher magnitudes. The MM5 model also shows similar feature in the day-2 and day-3 forecasts (middle panels). The WRF model forecasts feature overestimated rainfall all along the west coast of the peninsula, parts of northwestern and central India in all the forecasts. This feature is also prominent in the Eta model forecasts with higher magnitudes. In the MM5 model forecasts, the overestimated rain is prominent along the west coast (in day-2 and day-3) and northwest India (day-1).

\subsubsection{Bias score}

The bias score is the ratio of the frequency of forecast events to the frequency of observed events. The score values range from zero to infinity and the score of 1 implies a perfect forecast. It indicates whether the forecast system has a tendency to underpredict (bias less than 1) or overpredict (bias greater than 1) the events. Figure 14 shows the bias score computed for day-1, day-2 and day-3 rainfall forecasts. The T254 model forecasts (first column in figure 14) indicate near-perfect forecasts of rainfall mainly over parts of the Indian peninsula. Most of the central India from Gujarat to West Bengal (extending up to the Himalayas in the north) features overprediction of rainfall. Southern tip of the eastern peninsula also feature overprediction. The WRF model overpredicts the rainfall in the region of the southern tip of the peninsula in day-1, day-2 and day-3 forecasts. In comparison with the T254, the WRF model forecasts (particularly on day-2 and day-3) suggest greater area with correct forecasts of rainfall. The MM5 model (third column) overpredicts in northwest India, 

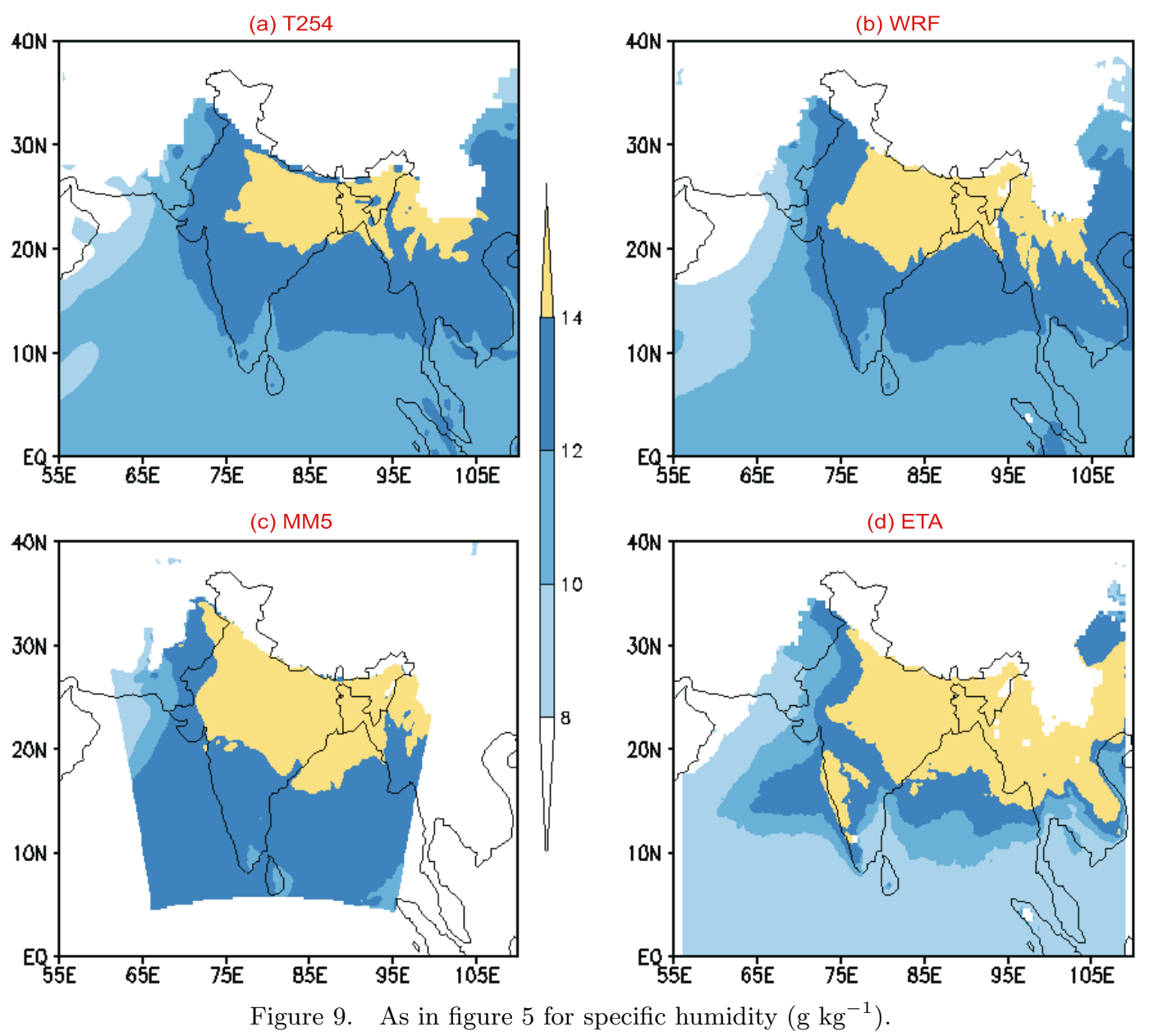

Gangetic Plains, and parts of eastern India in the day- 1 forecast. The day- 2 and day-3 forecasts feature widespread underprediction almost all over India. Eastern tip of the southern peninsula shows overprediction consistent with the T254 and WRF models. The Eta model forecasts (fourth column) on all days show underprediction over entire peninsula, all along the Gangetic Plains, and overprediction extending east to west (Orissa to Gujarat). The pattern of rainfall over- (under-) prediction to the south (north) between $20^{\circ}$ and $30^{\circ} \mathrm{N}$ in the Eta and WRF models indicate southward shift in the rainfall associated with monsoon trough.

\subsubsection{Probability of detection (hit rate)}

The probability of detection (POD) or simply the hit rate is the fraction of the observed 'yes' events that were also forecasted 'yes' events. The POD ranges from 0 to 1 and a score of 1 meaning perfect forecast. This score is sensitive to hits, but it ignores the false alarms. It is very sensitive to the climatological frequency of the event. This score is good for rare events. Figure 15 shows the POD computed for the forecasted rainfall from the four models. The POD values are low (high) over dry (wet) regions of the eastern (western) parts of the Western Ghats over the peninsula as shown in figure 15 . The POD values are very high $(>0.9)$ in all four models in the regions of high number of rainy days along the west coast and northeastern provinces and low over northwest India. The T254 and the WRF models show large parts of India with high POD values along the west coast, eastern parts of India, and parts of north India. The MM5 models' day-1 forecast shows similar characteristics to that of the WRF model and the T254 model. However, the day- 2 and day- 3 forecasts of MM5 show large parts with poor hit rate. The Eta model forecasts feature high hit rate all along the west coast similar to all the other model forecasts and an east-west pattern of high hit rate between $20^{\circ}$ and $25^{\circ} \mathrm{N}$. Large parts of Gangetic Plains and the peninsula feature poor hit rate in the Eta model forecasts.

\subsubsection{False alarm ratio}

The false alarm ratio (FAR) is a measure of fraction of predicted 'yes' events that actually did not occur 
DAY-3 FCST:Syserr Sp. Hum (g/kg) at $850 \mathrm{hPa}$ for JJAS, 08

(a) T254

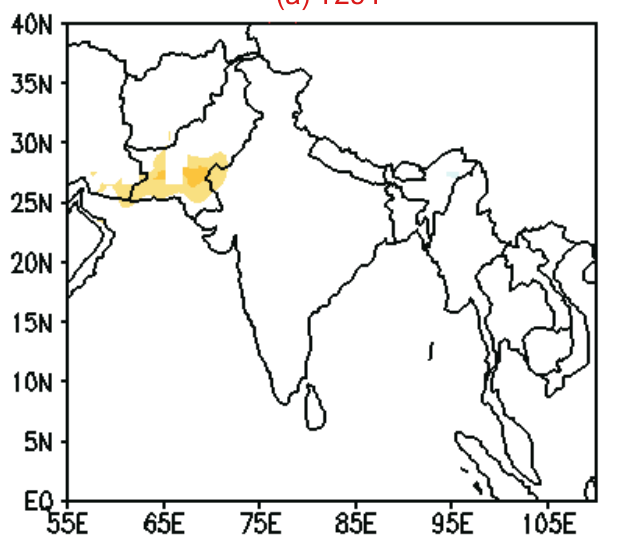

(c) MM5

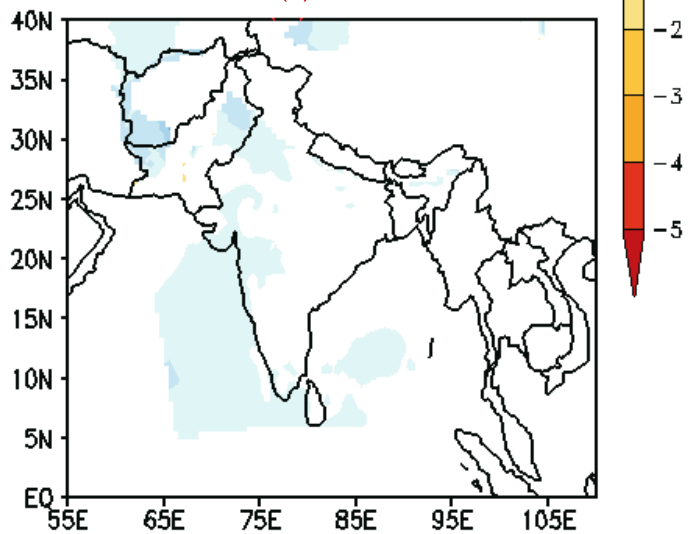

(b) WRF

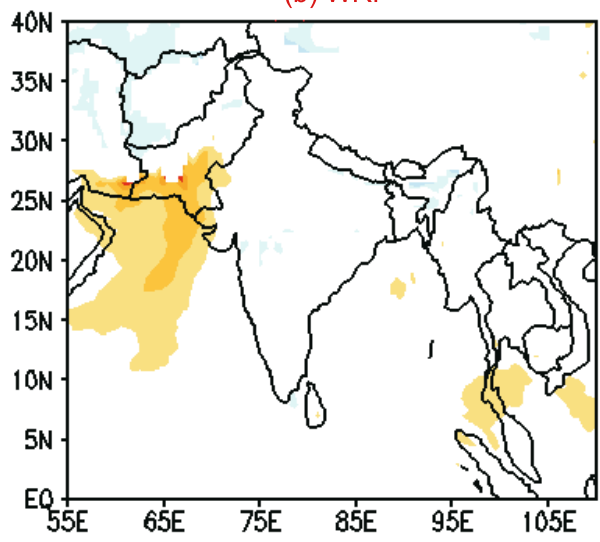

(d) ETA

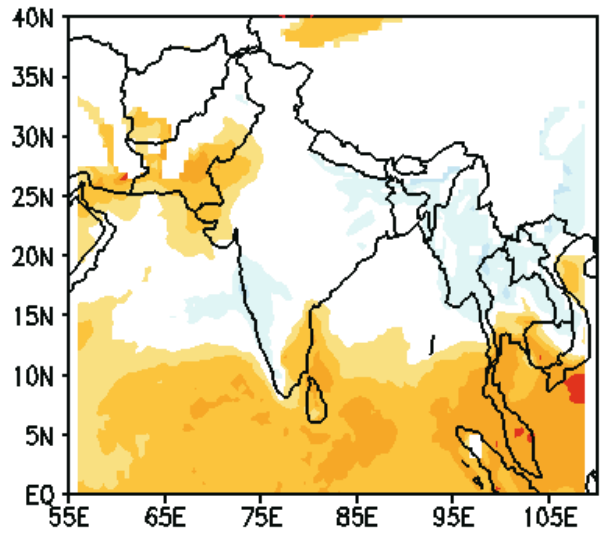

Figure 10. As in figure 6 for specific humidity $\left(\mathrm{g} \mathrm{kg}^{-1}\right)$.

Mesoscale Model Forecast Errors during June-Sept 2008

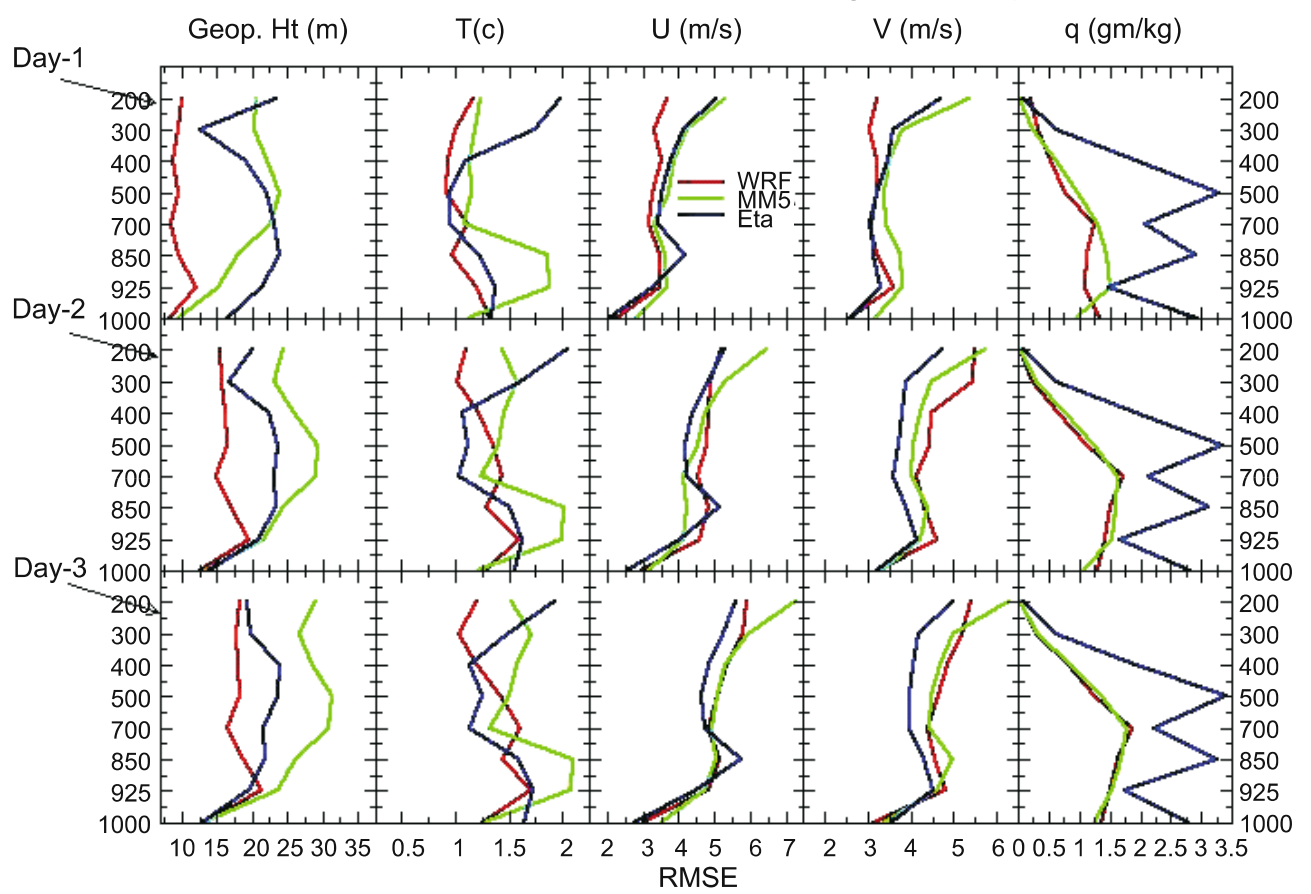

Figure 11. RMSE in day-1, day-2 and day-3 (rows 1-3) forecasts for geopotential height, temperature, zonal and meridional wind and specific humidity (columns $1-5)$ over Indian region $\left(8^{\circ}-38^{\circ} \mathrm{N} / 68^{\circ}-98^{\circ} \mathrm{E}\right)$. 



Figure 12. Observed and forecast (day-3) mean rainfall during JJAS 2008.

(i.e., false alarms). This score ranges from 0 to 1 and a score of 0 implies perfect forecast. This score is sensitive to false alarms, but it ignores the missed events. It is very sensitive to the climatological frequency of the event. Figure 16 shows the FAR computed for the forecast rainfall for all four models. All the four models indicate higher forecast skill along the west coast, northeastern states and along the foothills of Himalayas. All the models show very similar patterns over the dry regions with higher FAR values over the northwestern region and the southeastern tip of the peninsula. Overall, the FAR values are high (low) over the dry (wet) regions of peninsula suggesting a general poor skill of the models over dry regions.

\subsubsection{Probability of false detection (false alarm rate)}

The probability of false detection (POFD) or in simple words the false alarm rate is fraction of the observed 'no' events that were incorrectly forecast as 'yes' events. This score ranges from 0 to 1 and the perfect score is 0 . While it is sensitive to false alarms, it ignores the missed events. It includes the correct negatives in place of hits (in FAR). Figure 17 shows the POFD computed on forecast rainfall from four models. The POFD suggests low rate of false alarm over northwest India in each of the model forecasts. Inclusion of correct negatives gives a very different picture in the POFD compared to the FAR. West coast and eastern parts of India show high POFD in all the model forecasts indicating very poor performance by the models. All the models show good performance over northwest India. Eta model in particular stands out with large parts of northwest India, Gangetic Plains and eastern peninsula featuring very low values of POFD.

\subsubsection{Threat score (critical success index)}

The threat score (TS) or critical success index (CSI) tells us how well did the forecast 'yes' events correspond to the observed 'yes' events. This score 

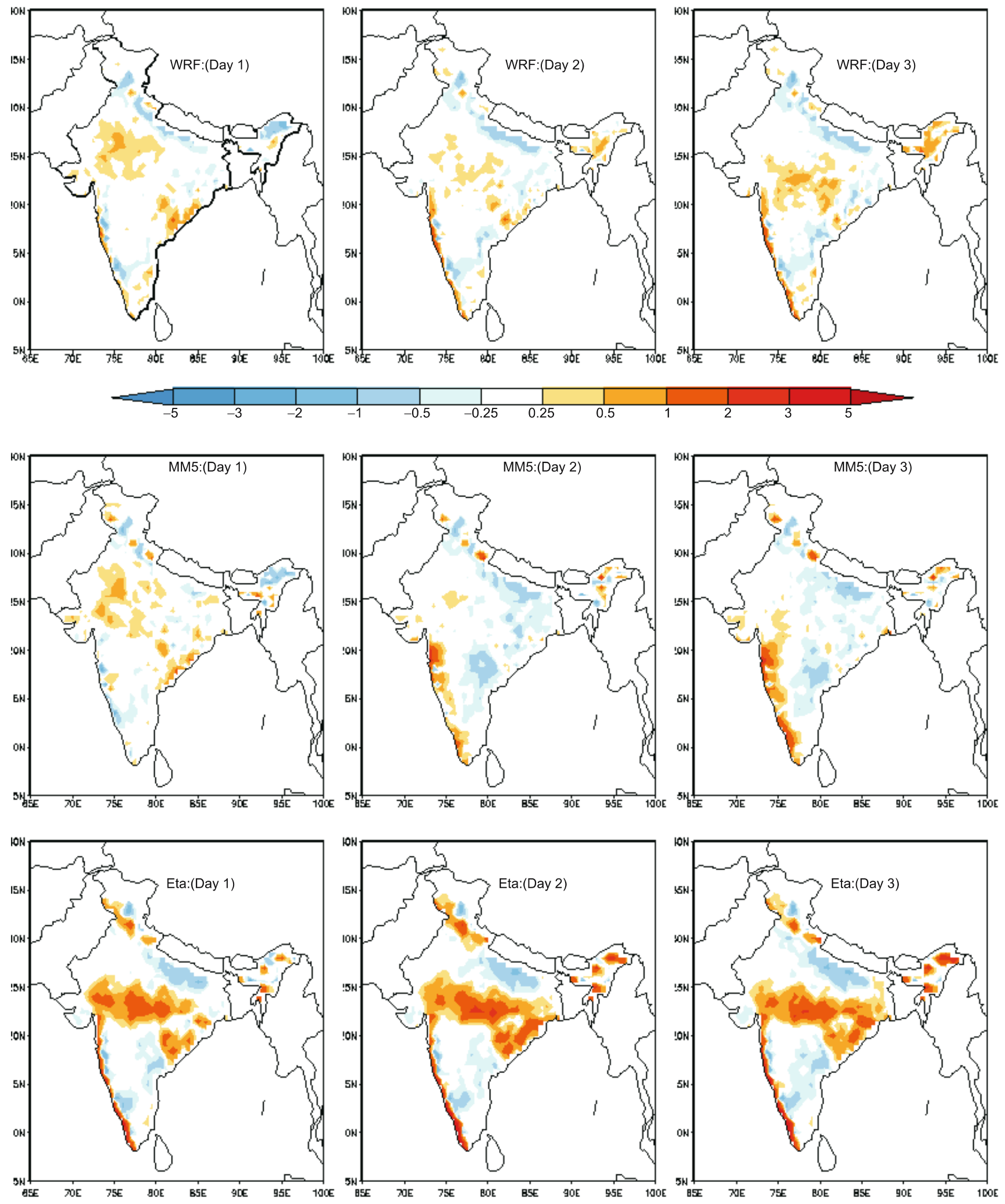

Figure 13. Forecast-observed rainfall differences (cm/day).

ranges from 0 to 1 ; where 0 indicates no skill and 1 indicates a perfect score. It is the accurate when correct negatives have been removed from consideration, i.e., the TS is only concerned with forecasts that count. This score is sensitive to hits while it penalizes both misses and false alarms. The 
TS does not distinguish source of forecast error. It depends on climatological frequency of events (poorer scores for rarer events) since some hits can occur purely due to random chance. Figure 18 shows the TS computed for the model forecasts rainfall. All models show high TS values (greater than 0.7) all along the west coast, parts of eastern India, hilly regions of north India and over northeastern region. The MM5 and the Eta model forecasts (day-2 and day-3) also indicate poor skill over north-west India and eastern peninsula.

\subsubsection{Equitable threat score (Gilbert skill score)}

The equitable threat score (ETS) is a standard skill score. Various weather services use the ETS to evaluate their precipitation forecasts above certain predefined thresholds of intensity of rain. This score tells us how well the forecast 'yes' events corresponded to the observed 'yes' events (accounting for hits due to chance). This score ranges from $-1 / 3$ to 1 . An ETS value of 0 indicates no skill and 1 meaning perfect score. This score measures the fraction of observed and/or forecast events that were correctly predicted, adjusted for hits associated with random chance (for example, it is easier to correctly forecast rain occurrence in a wet climate than in a dry climate). It is most suited for verification of rainfall in the NWP models because its 'equitability' allows fare comparison of the scores across different regimes. This score is sensitive to hits. It penalizes both the misses and the false alarms and does not distinguish the source of forecast error and it gives a lower score than TS. Figure 19 shows the ETS computed on the forecast rainfall from all models. The gray shading in the plots indicates no skill. The T254 model and the WRF model show similar skill over almost all parts of India. The day-1 forecasts of the MM5 model and the Eta model also indicate more or less comparable skill seen in the T254 model and the WRF model. However, the day-2 and day-3 forecasts of the MM5 model and the Eta model show very clear reduction in the skill with large parts showing no skill in the rainfall forecasts.

\subsubsection{Hanssen and Kuipers discriminant (true skill statistic, Peirces's skill score)}

The Hanssen and Kuipers (HK) score indicates how well did the forecasts separate the 'yes' events from the 'no' events? The score ranges from -1 to 1 with 0 indicating no skill and 1 indicating a perfect score. It uses all the elements of the contingency table. It does not depend on the climatological event frequency. The expression is identical to
HK $=$ POD - POFD. This score can also be interpreted as accuracy for events + accuracy for nonevents -1 . For rare events HK is unduly weighted towards the first term (same as POD), so this score may be more useful for frequent events. Figure 20 shows the HK scores computed on the forecast rainfall from all models. This figure shows higher score values along the west coast, Gujarat region, parts of north-west India and parts of Gangetic Plains in all the models. The WRF model day- 1 forecast shows large area with good skill compared to those in other three models. The Eta model and the MM5 model day- 2 and day- 3 forecasts show large parts with poor skill.

\subsubsection{Heidke skill score}

The Heidke skill score (HSS) gives the accuracy of the forecast relative to that of random chance. It measures the fraction of correct forecasts after eliminating those forecasts, which would be correct purely due to random chance. It ranges from minus infinity to 1 with 0 indicating no skill and 1 indicating a perfect score. This is a form of the generalized skill score, where the score in the numerator is the number of correct forecasts, and the reference forecast in this case is random chance. In meteorology, at least, random chance is usually not the best forecast to compare to - it may be better to use climatology (long-term average value) or persistence (forecast $=$ most recent observation, i.e., no change) or some other standard. Similar to the HK score HSS (figure 21) also suggests higher forecast skill for the WRF model than the T254 model over western India. The MM5 and the Eta model forecasts, particularly the day- 2 and day- 3 forecasts show poor skill.

\subsubsection{Odds ratio}

The odd ratio (OR) gives the ratio of the odds of an 'yes' forecast being correct, to the odds of an 'yes' forecast being wrong. The OR ranges from 0 to infinity, with a score of 1 indicating no skill and the perfect score is infinity. It measures the ratio of the odds of making a hit to the odds of making a false alarm. This score considers prior probabilities. It gives better scores for rarer events. It is less sensitive to hedging. This score is not to be used if any of the cells in the contingency table are equal to 0 . Figure 22 shows the OR computed for the model forecasts. Large regions in all the models show poor skill. The WRF model forecasts at all the lead times show better skill than the other models over western India as well as the Gangetic Plains south of Nepal. The day-2 and day-3 forecasts of the MM5 model show poor skill. 

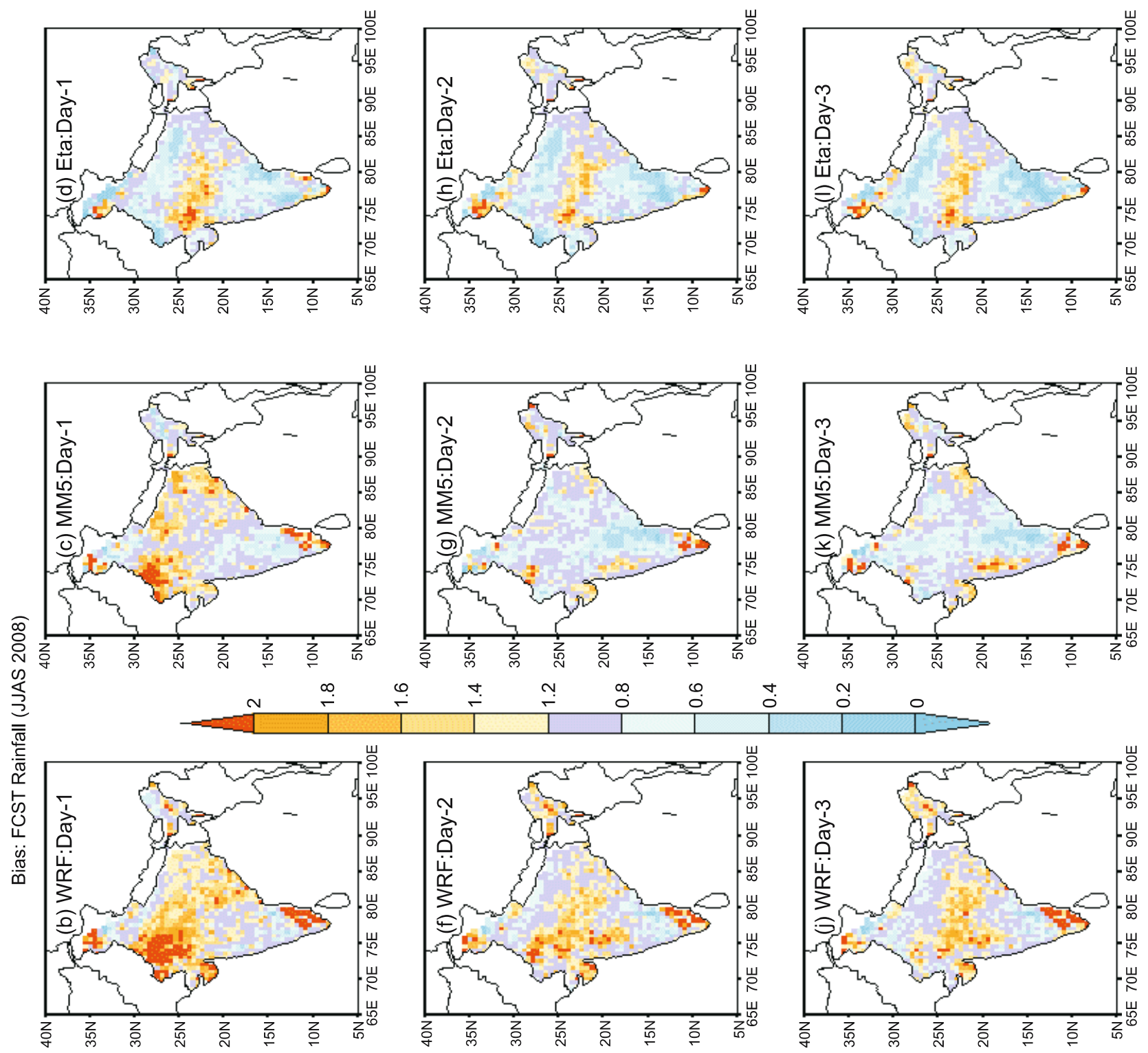

离
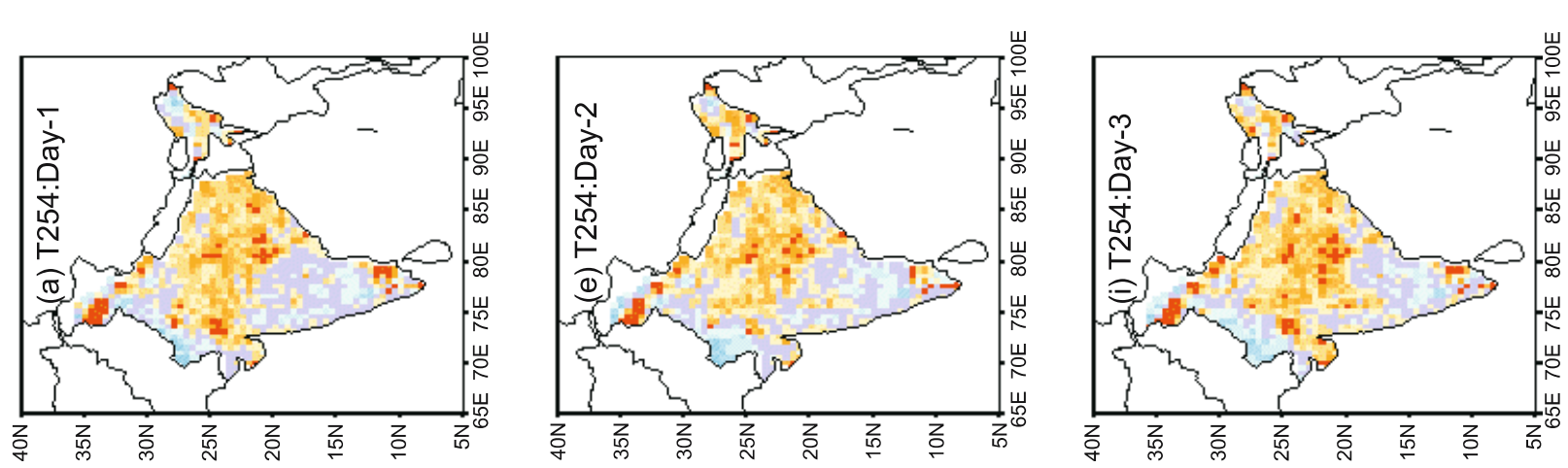

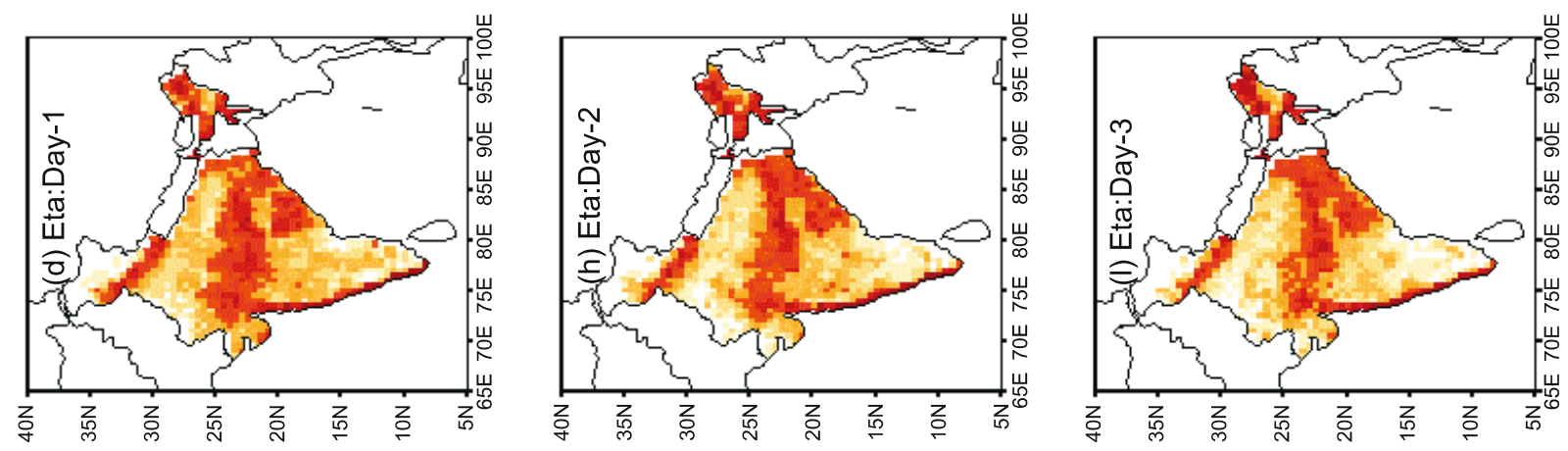

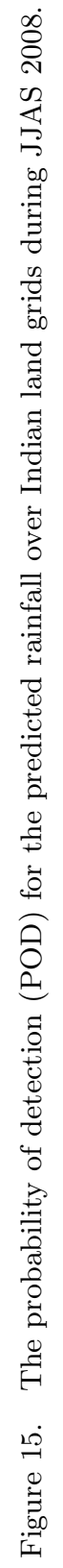
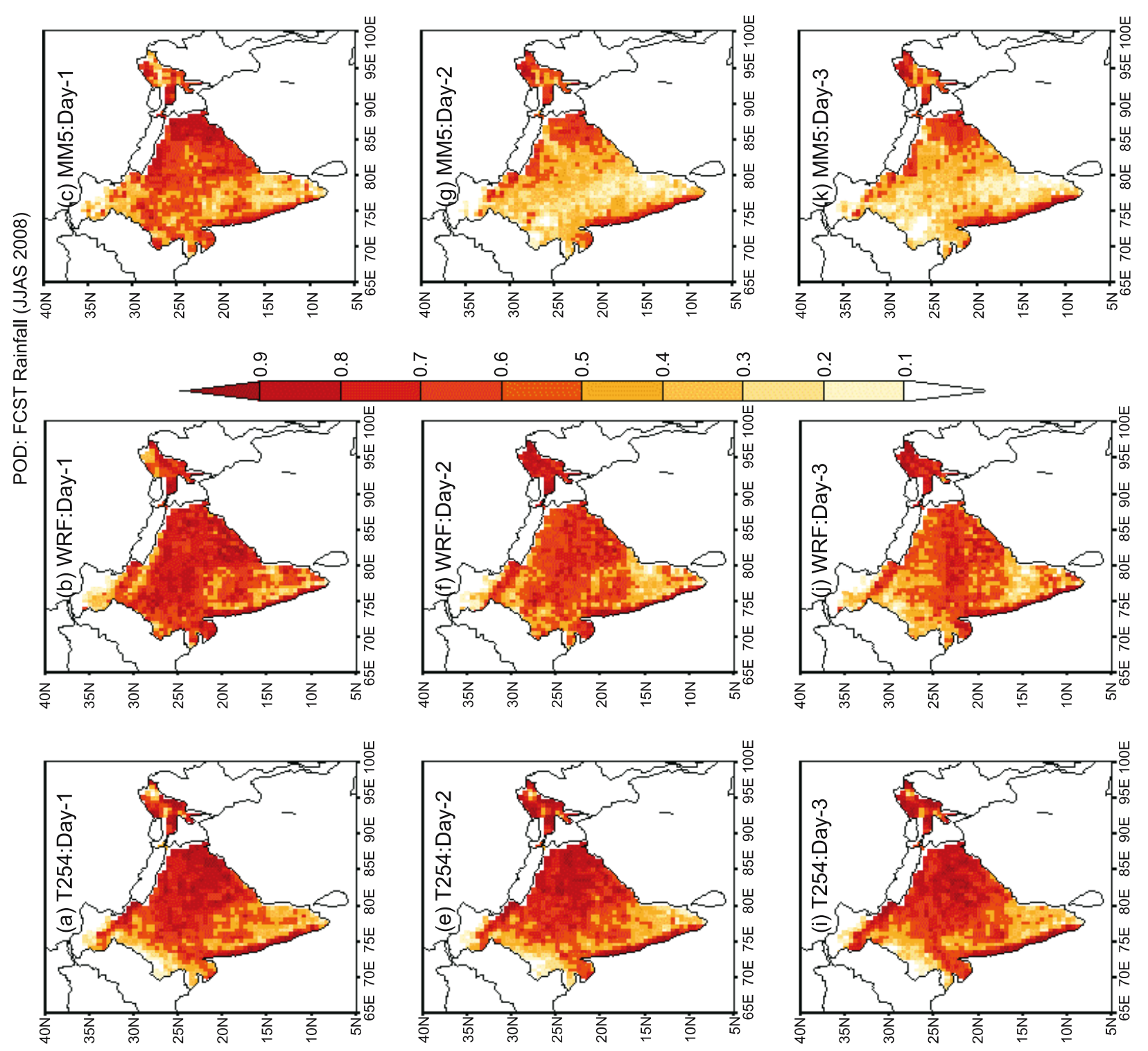

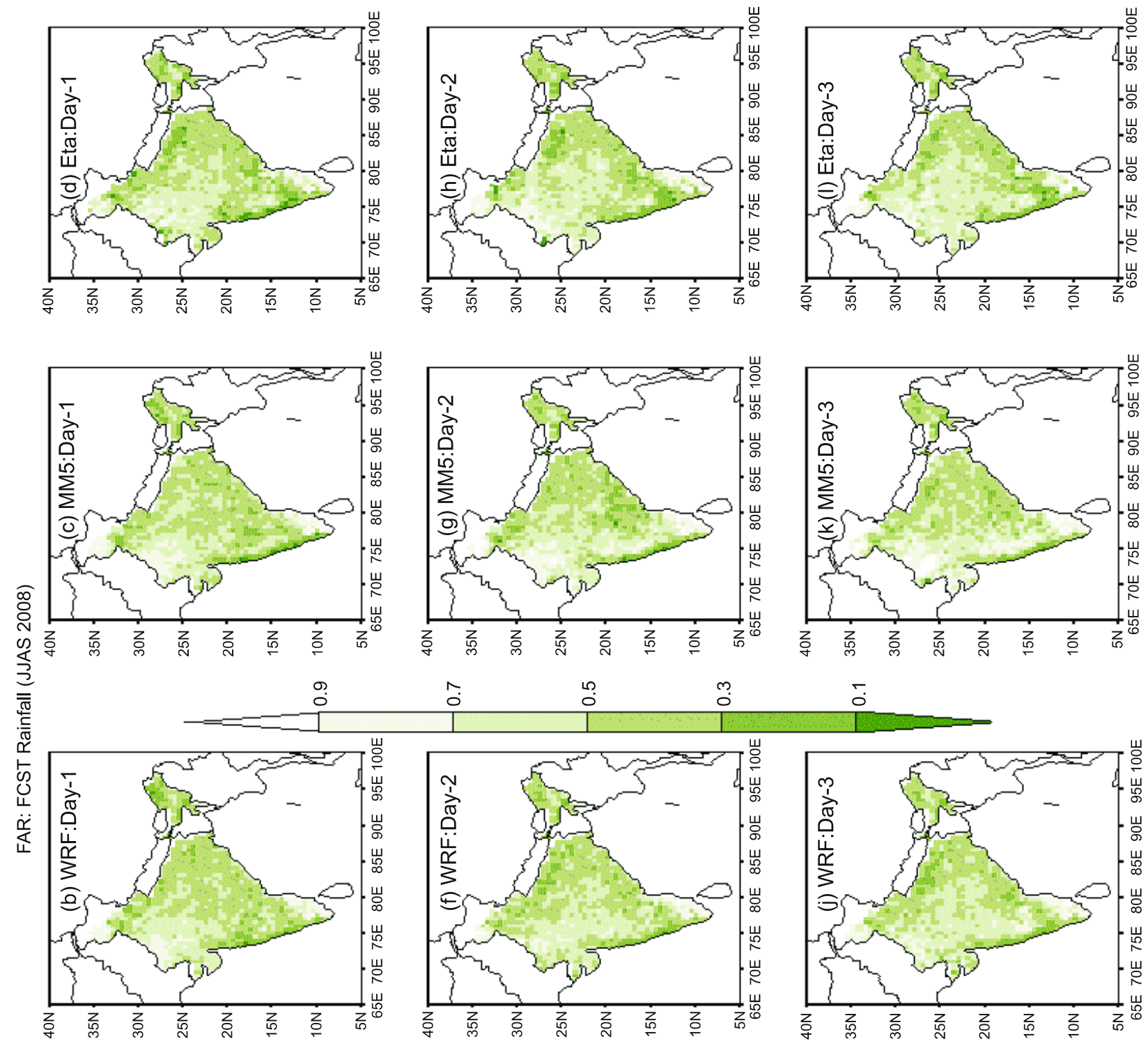

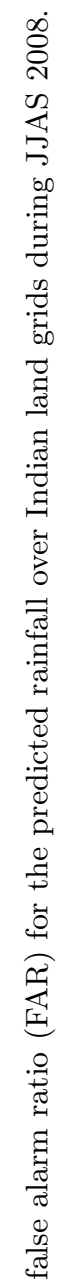
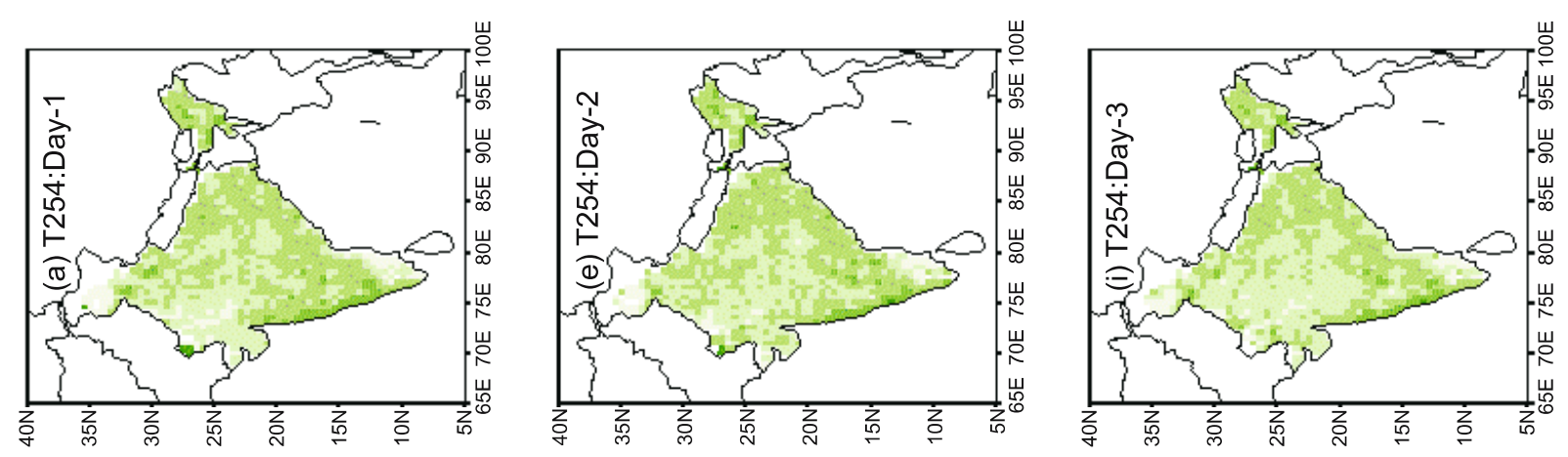

E

0
0
0
0
.0
.1 

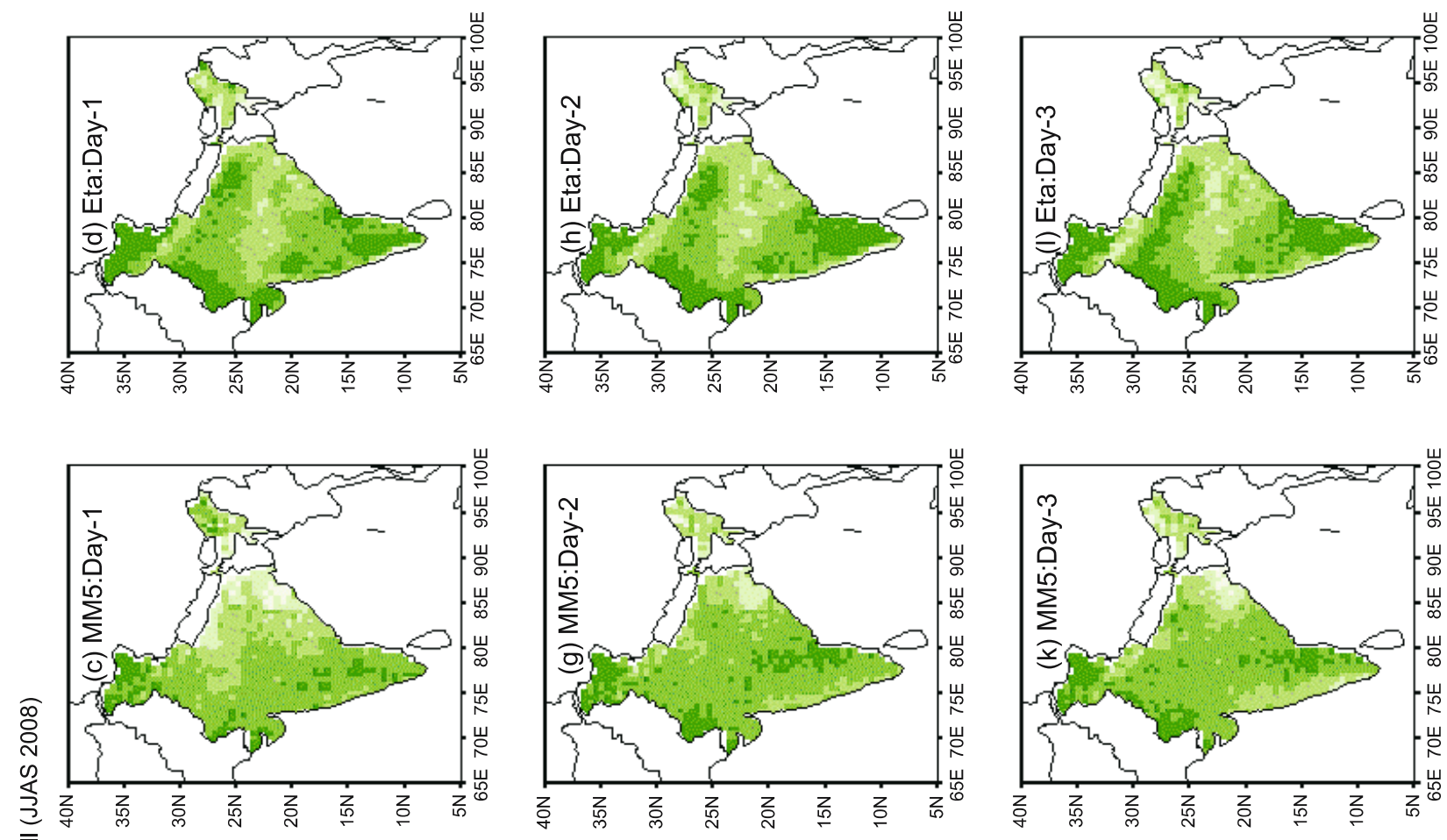

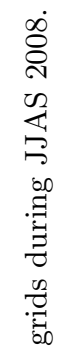
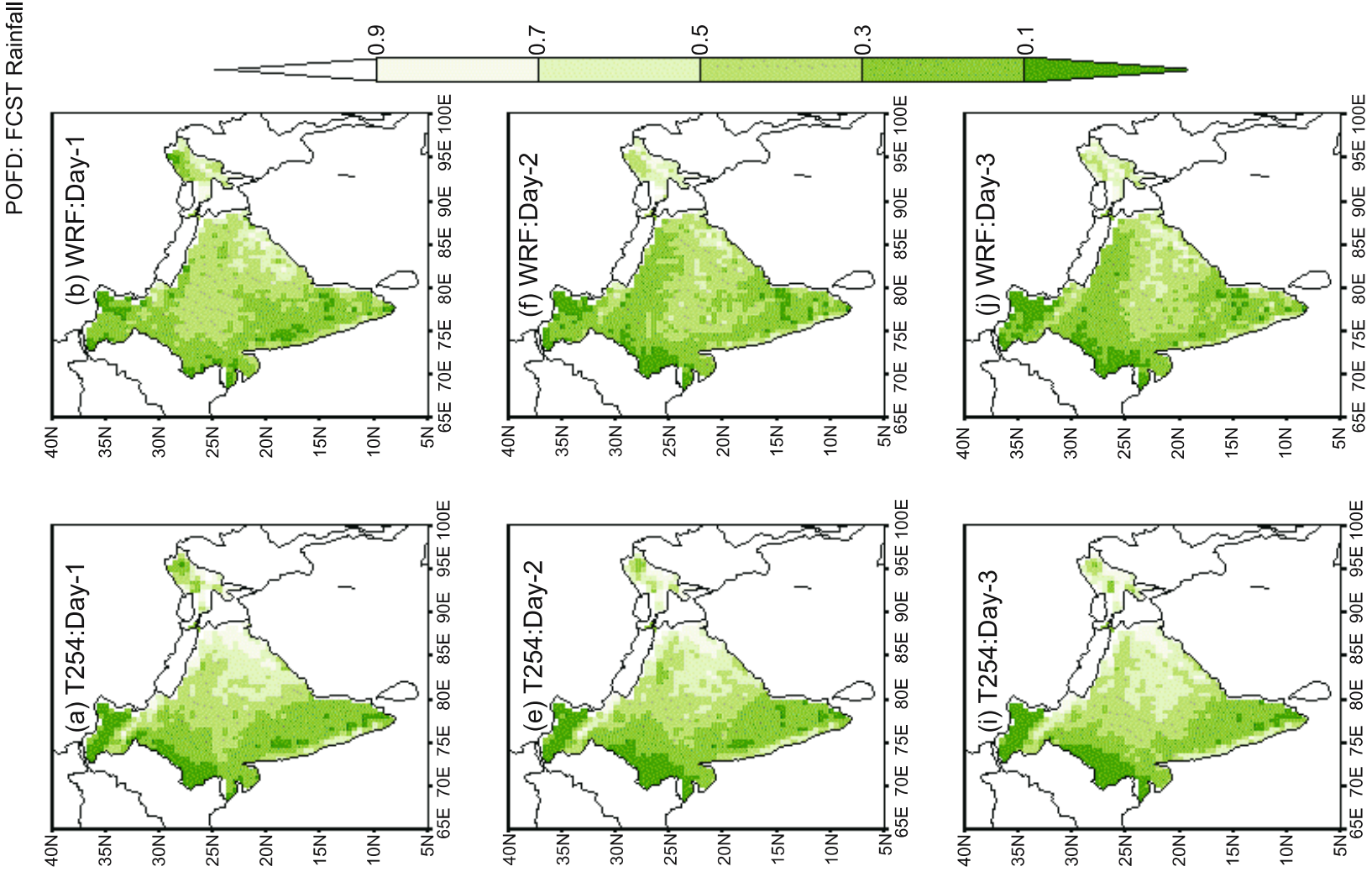

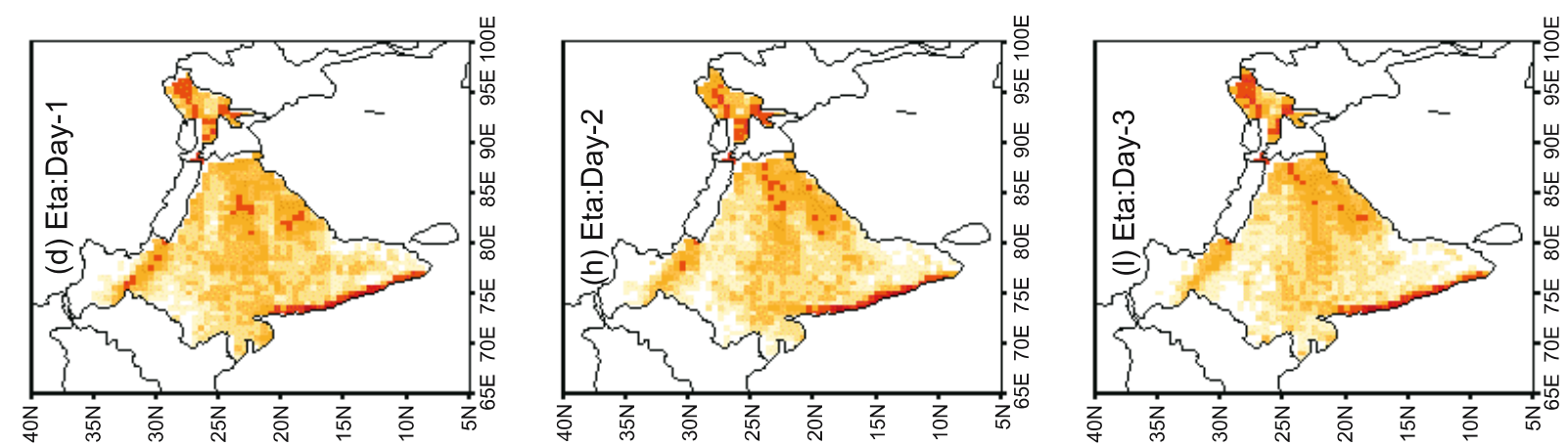

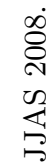
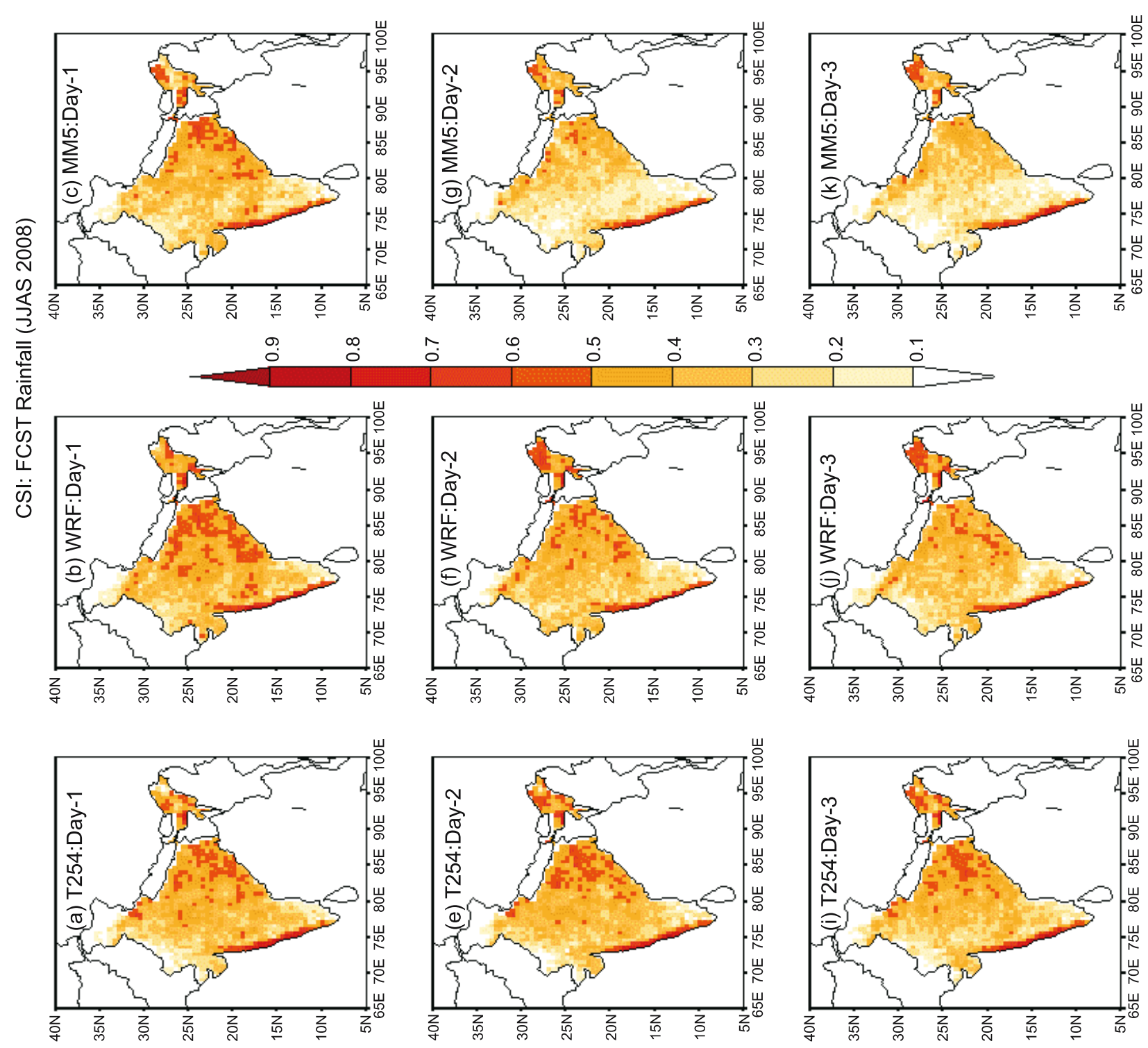

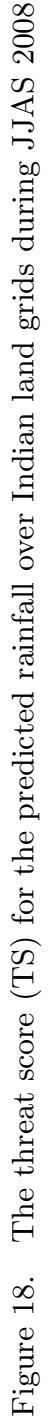





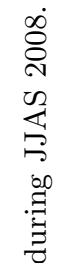


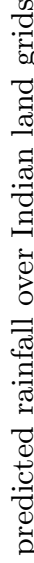
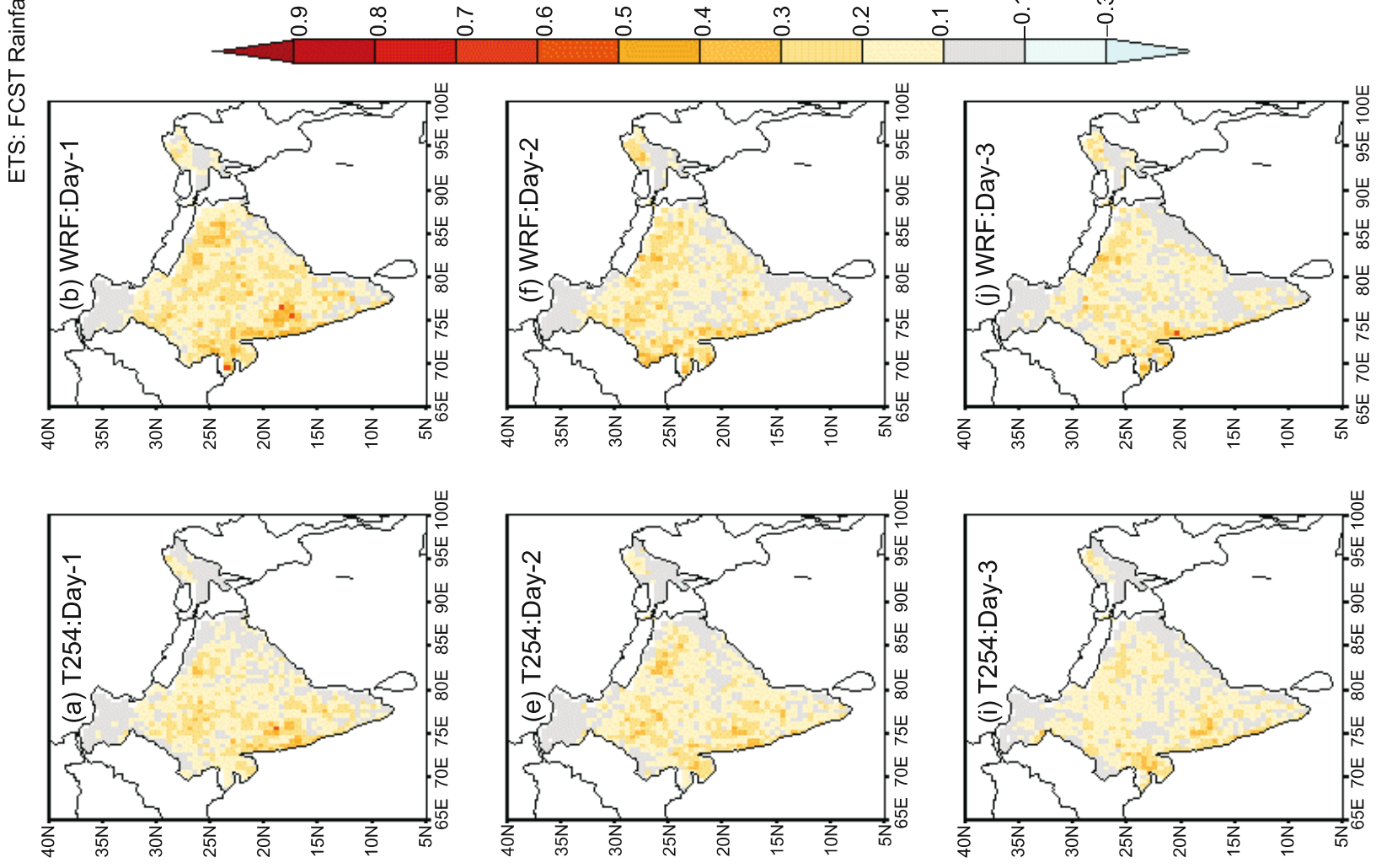

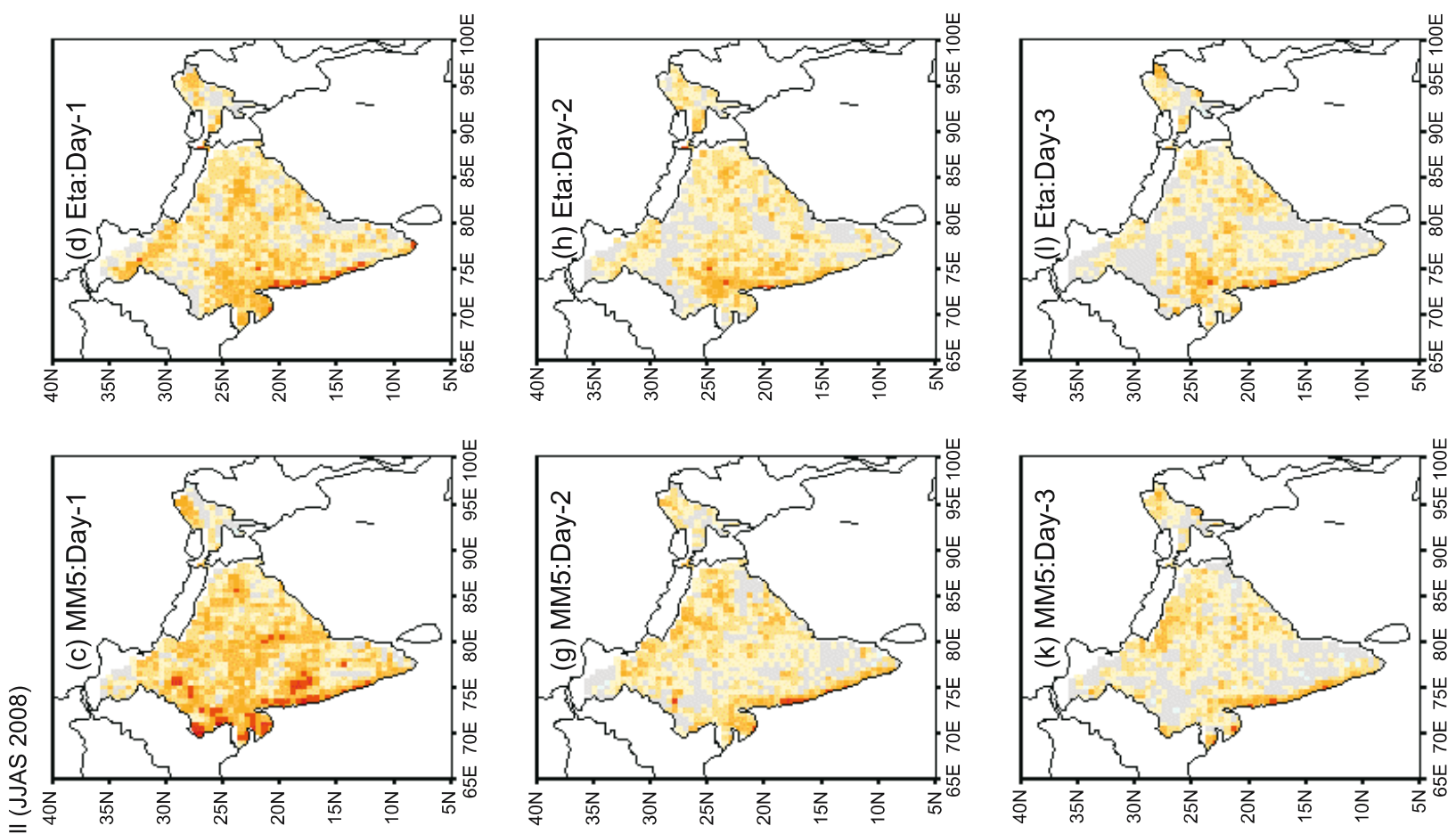

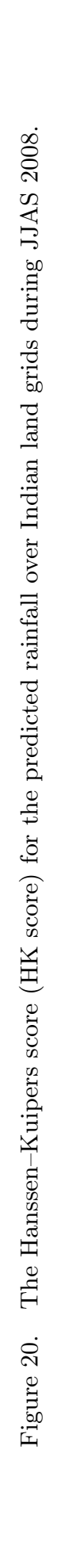
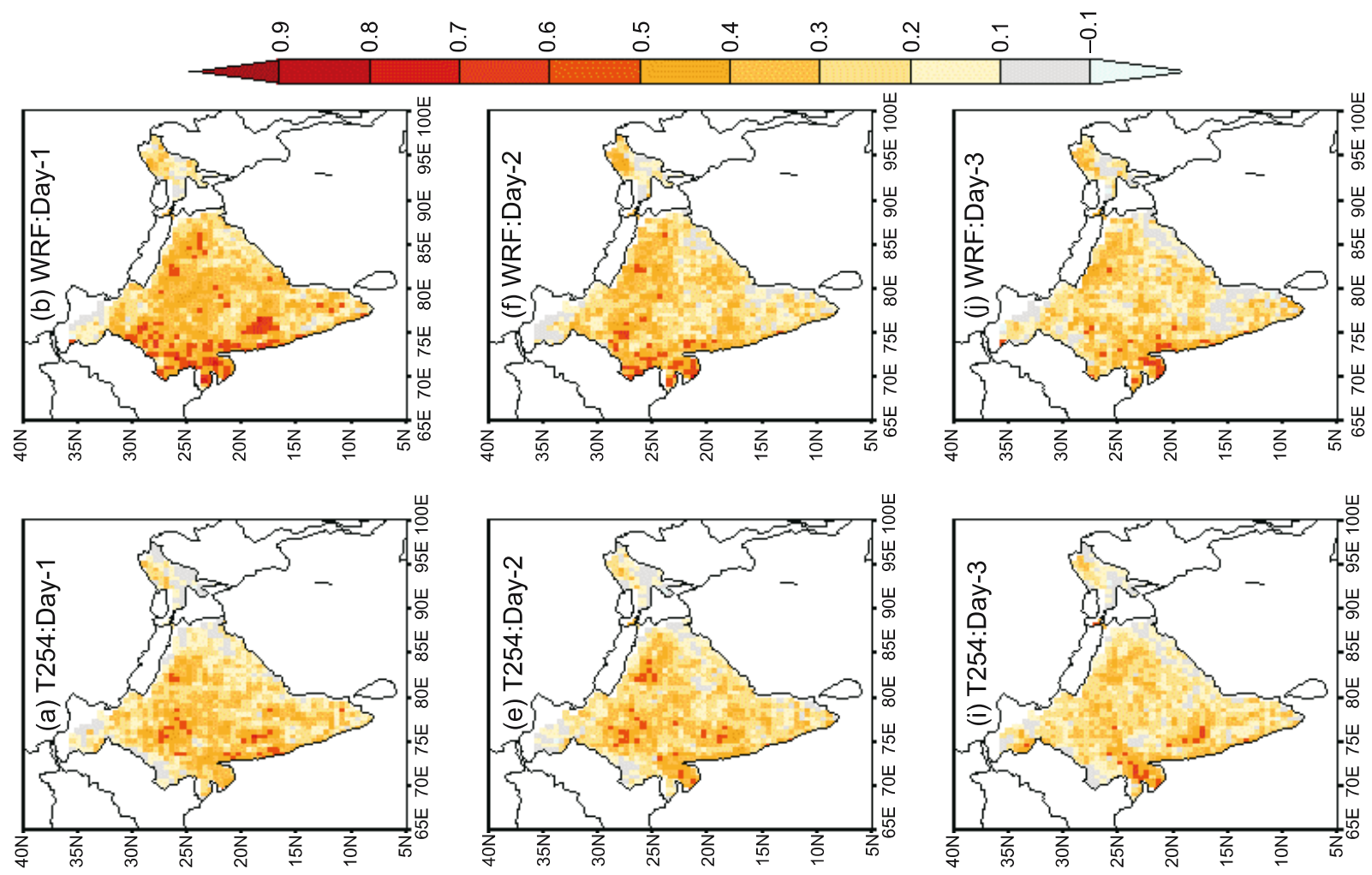

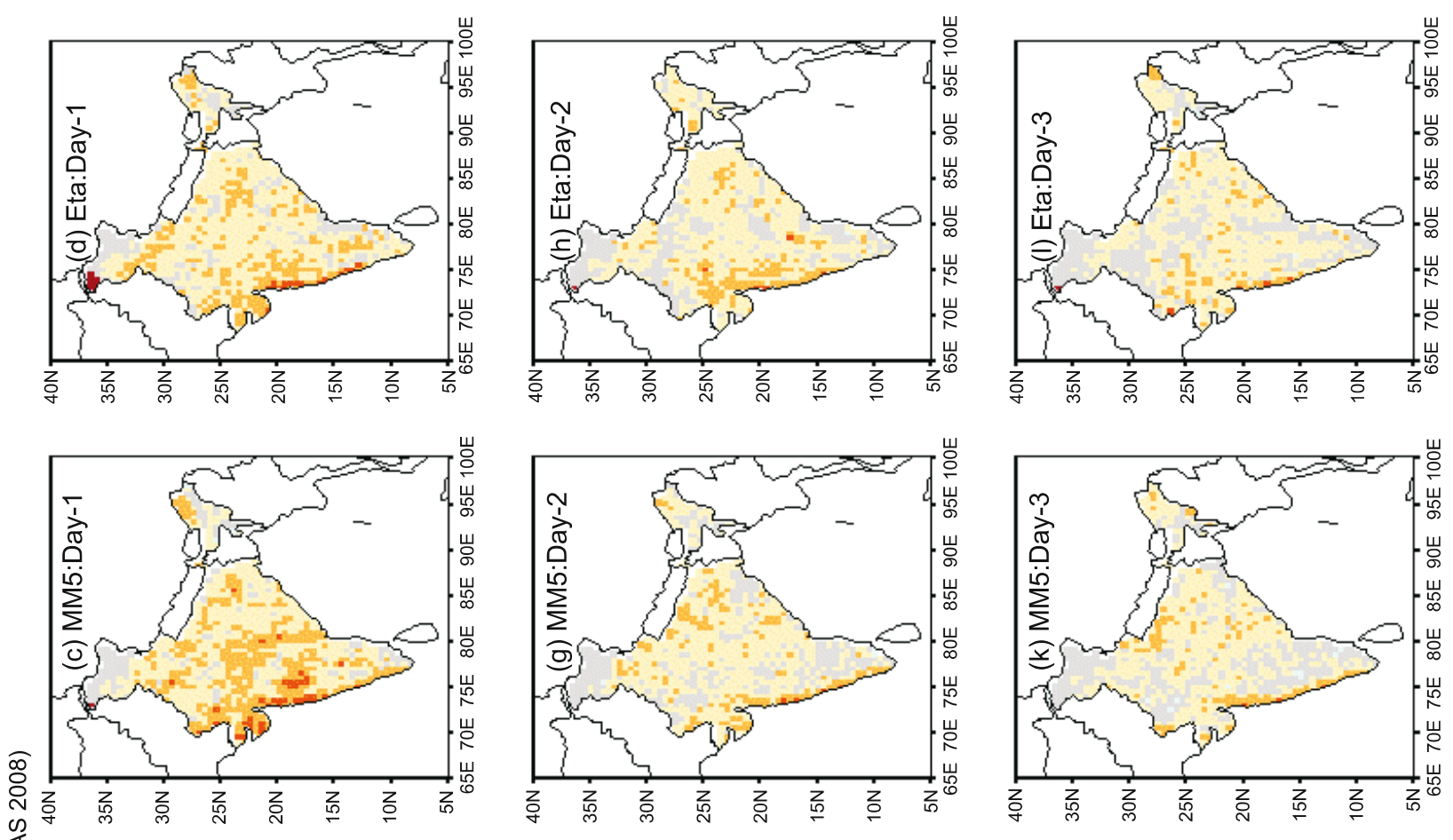

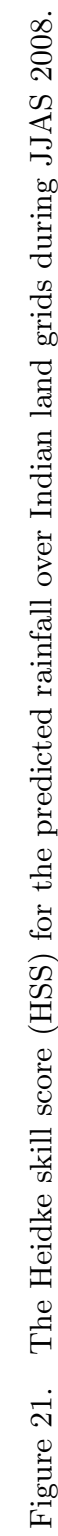
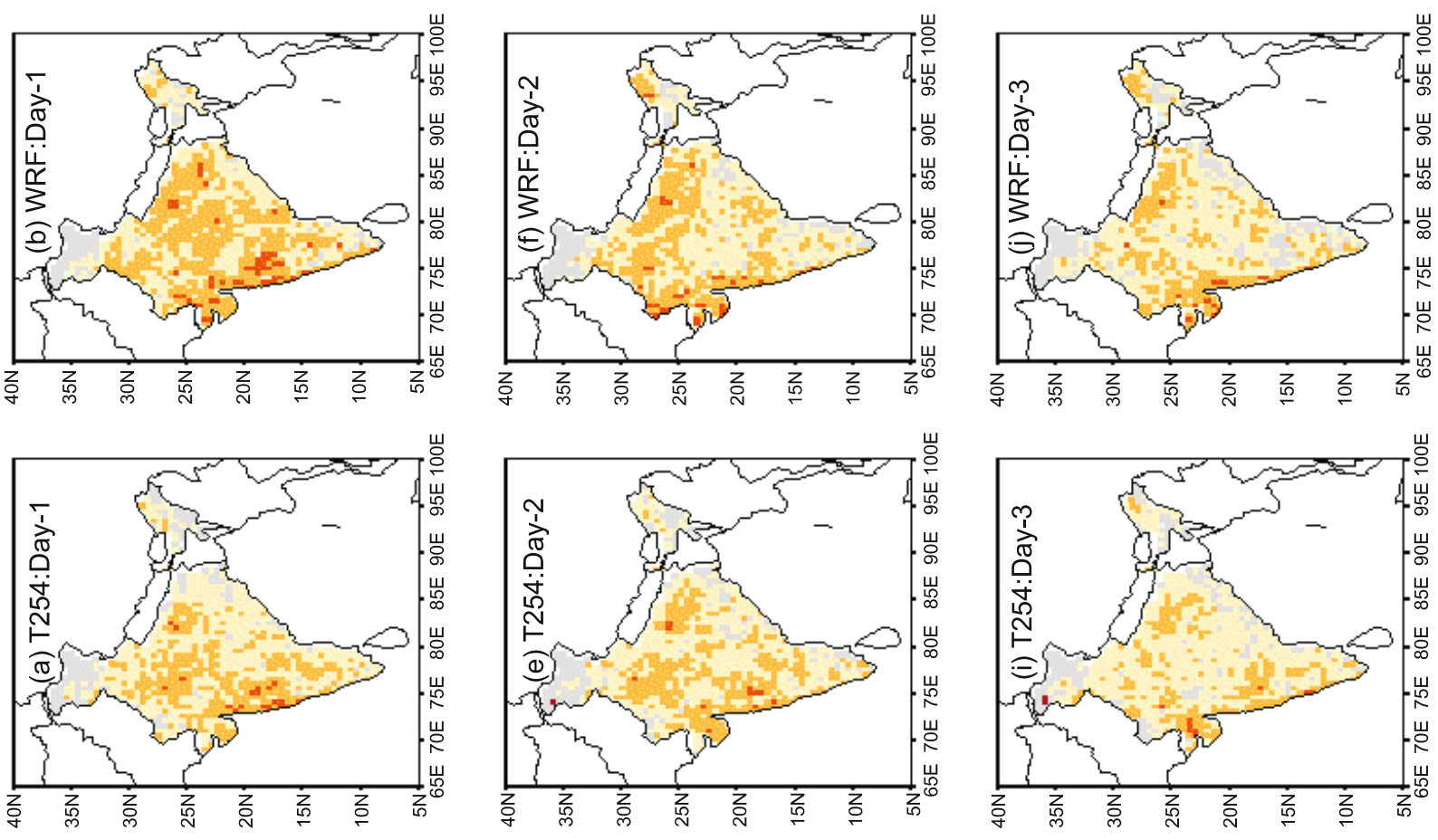

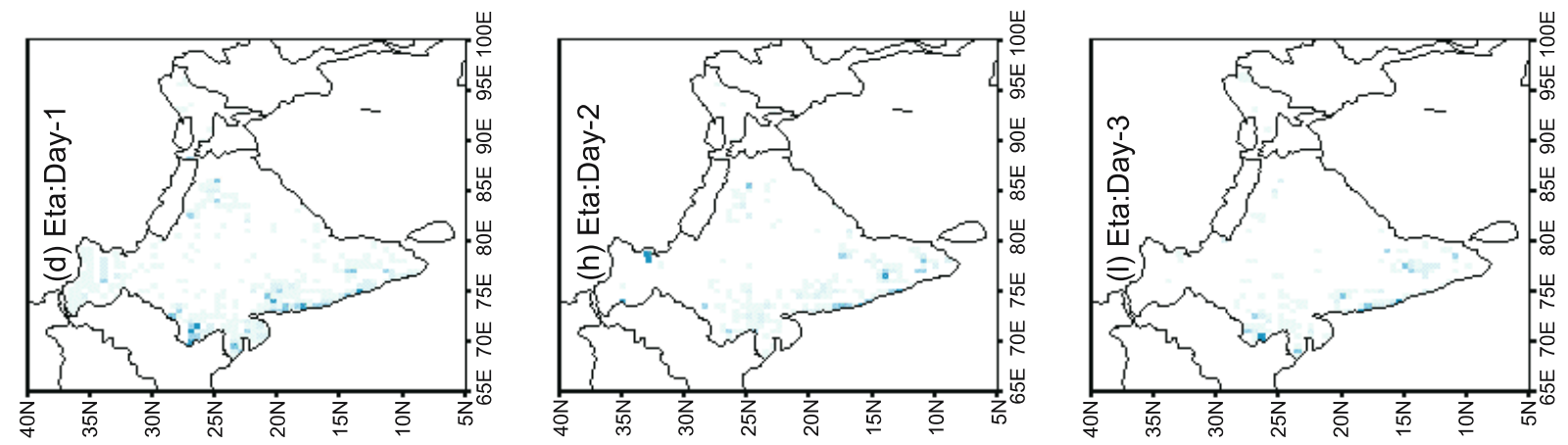

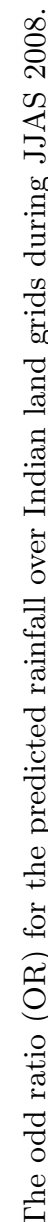
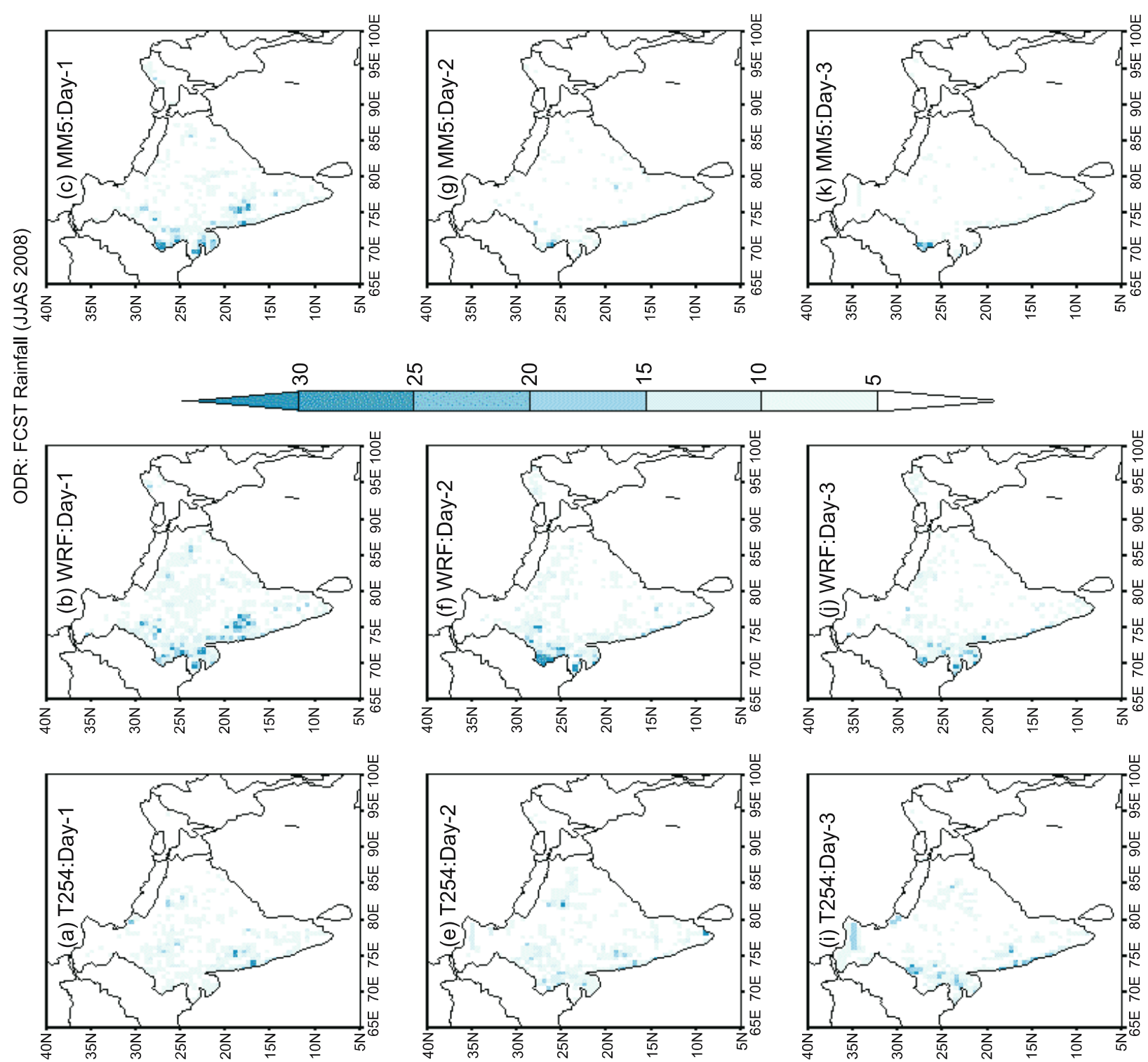

ำ 으 은
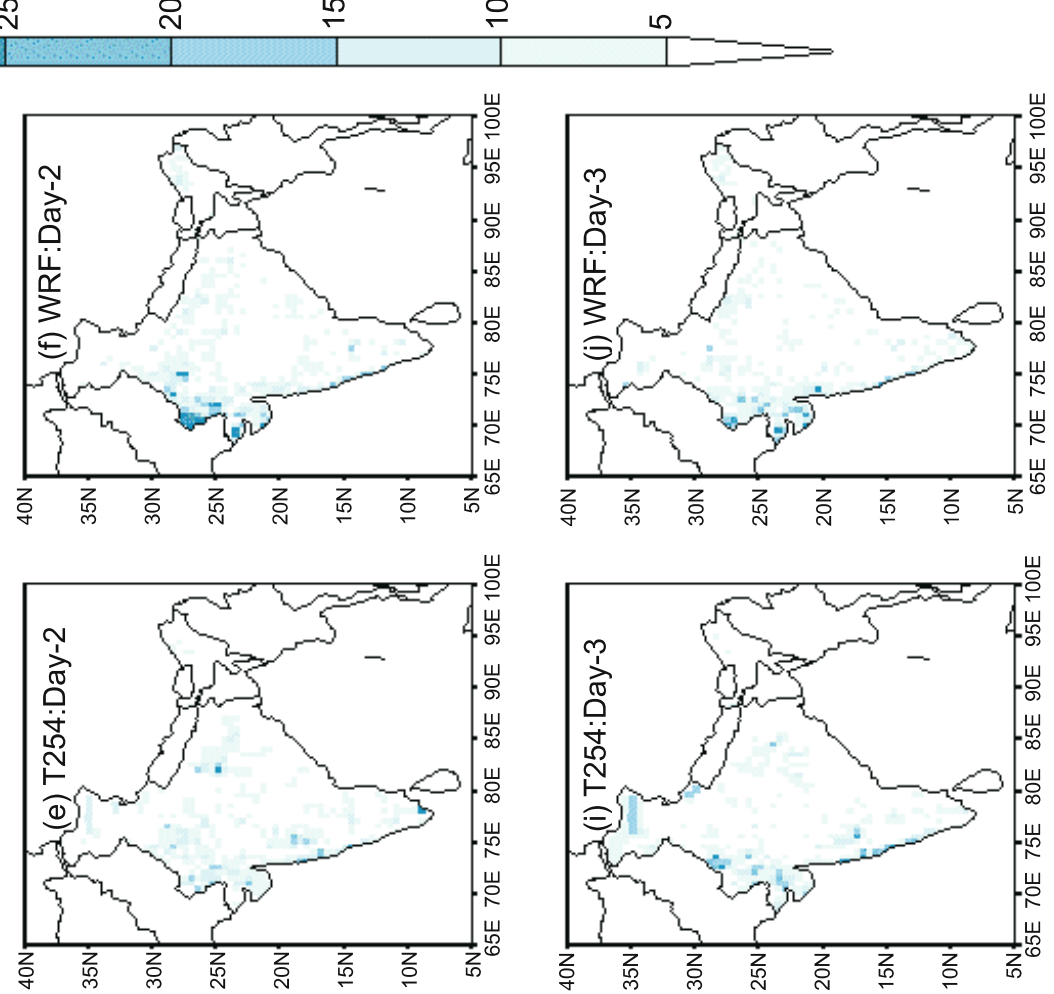

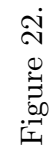




\section{Summary and conclusions}

The main aim of this study is to revisit the question addressed in Das et al (2008) as to which is the best mesoscale model suited for operational short-range prediction over India. We use the forecasts from the mesoscale models: the WRF model, the MM5 model, and the Eta model operational at NCMRWF. The mesoscale models use the real time T254 global analysis and forecast as initial and lateral boundary conditions. The systematic evaluation includes qualitative description and quantitative skill scores for identifying the best mesoscale model for India. Here we give the summary of the results:

- The JJAS 2008 mean analysis of the $850 \mathrm{hPa}$ circulation over the peninsula and Indo-Gangetic Plains is well captured. The analysis underestimates the peak winds in Somali Jet. The monsoon trough, the north-south temperature gradient at $850 \mathrm{hPa}$ and intense high temperature in the heat low are realistic in the analysis, although inter-model differences are evident. However, for the $850 \mathrm{hPa}$ specific humidity in the analysis, Eta model stands out with distinctly high magnitudes spread over large area in the domain.

- The JJAS 2008 forecast mean analysis of the $850 \mathrm{hPa}$ circulation shows realistic monsoon flow over the Arabian Sea, Indian peninsula and Bay of Bengal. However, the monsoon trough in the forecasts is rather weak. Over the Arabian Sea, systematic errors indicate easterly bias (to the north of mean flow) and westerly bias (to the south of mean flow). This suggests that the mesoscale model forecasts feature a monsoon current shifted southwards compared to the flow in the analysis. For the $850 \mathrm{hPa}$ temperature distribution, the systematic errors indicate that, by and large, the WRF model forecasts are dominated by warm bias and the MM5 model forecasts are dominated by cold bias. Features common to all the models include warm bias over northwest India and cold bias over southeast peninsula. The $850 \mathrm{hPa}$ specific humidity forecast errors clearly show that the Eta model features dry bias mostly over the sea, while MM5 features moist bias over large part of domain.

- The RMSE in the geopotential height (at all levels), temperature (below $700 \mathrm{hPa}$ ), and specific humidity at different levels clearly indicates that the WRF model forecasts feature least errors. The RMSE in the zonal and meridional winds show mixed results with different models showing least RMSE at different levels. The MM5 model features highest error in the predicted geopotential height (above $925 \mathrm{hPa}$ particularly on day-2 and day-3) temperature (between 925 and $700 \mathrm{hPa}$ on all days). The Eta model features highest error in predicted zonal wind at $850 \mathrm{hPa}$ on all days and specific humidity at all levels and on all days.

- A detailed assessment of the rainfall forecasts using statistical skill scores provide conclusive evidence in favour of the WRF model.

(a) Bias score shows large area of overpredicted rainfall in the T254 rainfall forecasts. WRF predictions feature relatively lesser area under the overprediction on all days. However, WRF (and MM5 model) shows higher magnitude of overprediction in the day-1 forecast over northwest India. The day-2 and day- 3 forecasts of the MM5 model feature underpredicted rainfall over most parts of India.

(b) The probability of detection (POD) or simply hit rate suggests poor detection in the Eta and the MM5 forecasts over large parts of peninsula and Gangetic Plains. On the other hand, the T254 and the WRF models clearly show higher detection compared to Eta and MM5 on all days. Overall, the POD values are low (high) over the dry (wet) regions of peninsula suggesting a general poor skill of the models over dry regions.

(c) The false alarm ratio (FAR) and probability of false detection (POFD) both show that the MM5 and the Eta model forecasts show marginally higher magnitude of FAR compared to that in the WRF and the T254 model forecasts. Overall, the FAR values are high (low) over the dry (wet) regions of peninsula suggesting a general poor skill of the models over dry regions. The picture is clearer in the POFD where the MM5 and the Eta models show larger area and magnitude with higher values of POFD compared to that in the WRF and the T254 model forecasts.

(d) Threat score (TS) or critical success index (CSI) and the equitable threat score (ETS) both suggest that the MM5 and the Eta model forecasts have poor skill compared to the forecasts of the WRF and the T254 models particularly on day- 2 and day- 3 .

(e) Hanssen and Kuipers (HK) and Heidke skill score (HSS) both show areas of higher skill in the WRF forecasts compared to even T254 model forecasts. The MM5 and Eta models consistently indicate poor skill particularly in day-2 and day-3.

The discussion clearly suggests that WRF modelling system is the best from among the studied 
mesoscale models. The improved initial conditions from the T254 model can explain large part of improvement in the WRF predictions. The latest and more advanced physics used in the WRF modelling system, not used in the MM5 and Eta models can explain the skill scores of the WRF model forecasts. The present study is able to bring out conclusively that the WRF model forecast skill is higher for prediction of circulation as well as the rainfall over the Indian land regions.

\section{Acknowledgements}

The authors are grateful to National Center for Atmospheric Research (NCAR), Boulder, Colorado, USA for making the WRF (WRF-ARW) model available to the modelling community. Thanks are due to the India Meteorological Department (IMD) for providing the rainfall analysis data used in this study. The comments and suggestions provided by the two reviewers are greatly appreciated. The reviewers have helped greatly in improving the quality of the paper. The authors express gratitude towards colleagues at NCMRWF for fruitful discussions and feedbacks during the preparation of this manuscript.

\section{References}

Ashrit R G, Das Gupta M and Bohra A K 2006 MM5 simulation of the 1999 Orissa Super Cyclone: Impact of bogus vortex on track and intensity prediction; Mausam 57 129-134.

Bhaskaran B, Jones R G, Murphy J M and Noguer M 1996 Simulations of the Indian summer monsoon using a nested climate model: Domain size experiments; Clim. Dyn. 12 573-587.

Bhaskar Rao D V, Ashok K and Yamagata T 2004 A numerical simulation study of the Indian summer monsoon of 1994 using NCAR MM5; J. Meteor. Soc. Japan 82(6) 1755-1775.

Bhaskar Rao D V and Hari Prasad D 2006 Numerical prediction of Orissa Supercyclone (1999): Sensitivity to the parameterization of convection, boundary layer and explicit moisture processes; Mausam 57 61-78.

Das S, Ashrit R and Moncrieff M W 2006 Simulation of a Himalayan Cloudburst event; J. Earth Syst. Sci. 115(3) 299-313.

Das S, Ashrit R, Moncrieff M W, Das Gupta M, Dudhia J, Liu C and Kalsi S R 2007 Simulation of intense organized convective precipitation observed during the Arabian Sea Monsoon Experiment (ARMEX); J. Geophys. Res. 112 D20117, doi:10.1029/2006JD007627.

Das S, Ashrit R, Gopal R Iyengar, Saji Mohandas, Das Gupta M, John P George, Rajagopal E N and Surya Kanti Dutta 2008 Skills of different mesoscale models over Indian region during monsoon season: Forecast errors; J. Earth Syst. Sci. 117(5) 603-620.

Dash S K, Shekhar M S and Singh G P 2006 Simulation of Indian summer monsoon circulation and rainfall using RegCM3; Theor. Appl. Climatol. 86 161-172.
Findlater J 1969 A major low level air current near the Indian ocean during the northern summer; Quart. J. Roy. Meteor. Soc. 95 362-380.

Grell G A, Kuo Y-H and Pasch R 1991 Semi-prognostic tests of cumulus parameterization schemes in the middle latitudes; Mon. Wea. Rev. 119 5-31.

Janjic Z I 1994 The step-mountain Eta coordinate model: Further developments of the convection, viscous sublayer and turbulence closure schemes; Mon. Wea. Rev. 122 927-945.

Janjic Z I 2000 Comments on "Development and Evaluation of a Convection Scheme for Use in Climate Models"; J. Atmos. Sci. 573686.

Ji Y and Vernekar A D 1997 Simulation of the Asian summer monsoons of 1987 and 1988 with a regional model nested in a global GCM; J. Climate 10 1965-1979.

Kain J S and Fritsch J M 1990 A one-dimensional entraining/detraining plume model and its application in convective parameterization; J. Atmos. Sci. 47 2784-2802.

Kain J S and Fritsch J M 1993 Convective parameterization for mesoscale models: The Kain-Fritcsh scheme, the representation of cumulus convection in numerical models, (eds) Emanuel K A and Raymond D J, Amer. Meteor. Soc., $246 \mathrm{pp}$.

Litta A J and Mohanty U C 2008 Simulation of a severe thunderstorm event during the field experiment of STORM of 2006, using WRF-NMM model; Curr. Sci. 95(2) 204-215.

Mandal M and Mohanty U C 2006 Numerical experiments for improvement in the mesoscale simulation of Orissa super cyclone; Mausam $\mathbf{5 7}$ 79-96.

Mohanty U C, Mandal M and Raman S 2004 Simulation of Orissa supercyclone (1999) using PSU/NCAR mesoscale model; Natural Hazards 31 373-390.

Pan H-L and Wu W-S 1995 Implementing a mass flux convection parameterization package for the NMC Medium-Range Forecast Model; NMC Office Note, No. 409, 40pp.

Pant G B and Rupa Kumar K 1997 Climates of South Asia (Chichester, UK: John Wiley \& Sons) 344pp.

Patra P K, Santhanam M S, Potty K V J, Tewari M and Rao P L S 2000 Simulation of tropical cyclones using regional weather prediction models; Curr. Sci. $\mathbf{7 9 ( 1 )}$ 70-78.

Pattanayak S and Mohanty U C 2008 A comparative study on performance of MM5 and WRF models in simulation of tropical cyclones over Indian seas; Curr. Sci. 95(7) 23-36.

Pattanayik D R and Rama Rao Y V 2009 Track prediction of very severe cyclone 'Nargis' using high resolution weather research forecasting (WRF) model; J. Earth Syst. Sci. 118(4) 309-329.

Rajeevan M, Bhate J, Kale J D and Lal B 2005 Development of a high resolution daily gridded rainfall data for the Indian region (Met Monograph Climatology, 22/2005, 26 pp, available from India Meteorological Department, Pune, India).

Rajeevan M and Jyoti Bhate 2008 A high resolution daily gridded rainfall data set (1971-2005) for mesoscale meteorological studies; NCC (9) Research Report. India Meteorological Department, Pune.

Rajagopal E N and Iyengar G R 2002 Implementation of Mesoscale ETA model at NCMRWF; NCMRWF Research Report No. NMRF/RR/4/2002.

Rajagopal E N and Iyengar G R 2005 Mesoscale forecasts with Eta model over Indian region; Curr. Sci. 88(6) 906-912.

Rajagopal E N, Das Gupta M, Mohandas S, Prasad V S, George J P, Iyengar G R and Preveen Kumar D 2007 
Implementation of the T254L64 Global Forecast System at NCMRWF. NMRF/TR/1/2007. NCMRWF, A-50, Sector-62, Noida (UP)-201307, India.

Rakesh V, Singh R, Pal P K and Joshi P C 2007 Sensitivity of mesoscale model forecast during a satellite launch to different cumulus parameterization schemes in MM5; Pure Appl. Geophys. 164 1617-1637.

Ratnam J V and Kumar K K 2005 Sensitivity of the simulated monsoons of 1987 and 1988 to convective parameterization schemes in MM5; J. Climate 18 2724-2743.
Singh R, Pal P K, Kishtawal C M and Joshi P C 2005 Impact of bogus vortex on track and intensity prediction of tropical cyclone; J. Earth Syst. Sci. 114 427-436.

Trivedi D K, Mukhopadhyay P and Vaidya S S 2006 Impact of physical parameterization schemes on the numerical simulation of Orissa super cyclone (1999); Mausam $5 \mathbf{7}$ 97-110.

WWRP 2009-1 2009 Recommendations from the verification and intercomparison of QPFs and PQPFs from the operational NWP models. WMO TD No. 1485, p37. 